CUADERNOS DE ESTUDIOS GALLEGOS, LXI

Núm. 127 (enero-diciembre 2014), págs. 81-115

ISSN: $0210-847 \mathrm{X}$

DOI: $10.3989 /$ ceg.2014.127.03

\title{
HIDALGOS DEL RIBEIRO DE AVIA: LA CASA DE CANDENDO EN SAN MIGUEL DE LEBOSENDE (LEIRO), SIGLOS XVI-XVII*
}

\author{
IAgo Rodríguez PALMEIRO \\ Universidad de Santiago de Compostela
}

\begin{abstract}
* Este trabajo se inscribe en el marco del Proyecto de Investigación "Parroquia y comunidad rural en Galicia, c. 1450-c. 2000, código: HAR2009-13304/HIST", financiado por el Ministerio de Economía y Competitividad y está subvencionado con una beca perteneciente al Subprograma de Formación del Personal Investigador (BES-2010-032147), dependiente del Ministerio de Economía y Competitividad. Las siglas y abreviaturas empleadas en él son las siguientes: art. cit $=$ artículo citado; ed., eds. = edición / editor, -a, ediciones / editores, -as; dir., dirs. = director, -a / directores, -as; ibíd. = ibídem; íd. = ídem; núm., núms. = número(s); op. cit. = obra citada; pág., págs. = página(s); t., ts. = tomo(s); v. = véase, vide. Queremos agradecer la colaboración del profesor Pegerto Saavedra Fernández y el apoyo documental del Archivo Histórico Universitario de Santiago en la elaboración de este artículo.
\end{abstract}




\title{
HIDALGOS DEL RIBEIRO DE AVIA: LA CASA DE CANDENDO EN SAN MIGUEL DE LEBOSENDE (LEIRO), SIGLOS XVI-XVII
}

\section{RESUMEN}

El propósito de este artículo es dar a conocer los primeros resultados de nuestras investigaciones al respecto de la familia González Candendo, oriunda de San Miguel de Lebosende, ayuntamiento de Leiro. Su historia se remonta hasta finales del siglo XVI y concluye en los inicios del XVIII, con su unión a una rama secundaria de los Garza Quiroga de Tor. A tal efecto, basaremos nuestro análisis en dos puntos principales: la genealogía y el patrimonio, pilares fundamentales para comprender el origen y la evolución socio-económica de sus miembros. Con ello pretendemos brindar una pequeña contribución al conocimiento de este grupo social en el área rural orensana y, por extensión, en la Galicia interior.

PAlabras Clave: Hidalguía, genealogía, economía, capellanía, obra pía.

\section{FIDALGOS DO RIBEIRO DE AVIA: A CASA DE CANDENDO EN SAN MIGUEL DE LEBOSENDE (LEIRO), SÉCULOS XVI-XVII}

\section{RESUMO}

O propósito deste artigo é dar a coñecer os primeiros resultados das nosas investigacións respecto da familia González Candendo, oriúnda de San Miguel de Lebosende, concello de Leiro. A súa historia remóntase até finais do século XVI e conclúe nos inicios do XVIII, coa súa unión a unha rama secundaria dos Garza Quiroga de Tor. Con tal obxecto, basearemos a nosa análise en dous puntos principais: a xenealoxía e o patrimonio, alicerces fundamentais para comprender a orixe e a evolución socioeconómica dos seus membros. Con iso pretendemos brindar unha pequena contribución ao coñecemento deste grupo social na área ourensá e, por extensión, na Galicia rural interior. PAlABRAS ClaVE: Fidalguía, xenealoxía, economía, capelanía, obra pía.

\section{NOBILITY OF THE RIBEIRO DE AVIA: THE HOUSE OF CANDENDO IN SAN MIGUEL DE LEBOSENDE (LEIRO), $16^{\mathrm{TH}}-17^{\mathrm{TH}}$ CENTURIES}

\begin{abstract}
The purpose of this article is to present the first results of our investigations concerning the Gonzalez Candendo family, native to San Miguel de Lebosende, council of Leiro. Its history goes back to the late sixteenth century and ends in the early eighteenth, with its union to a secondary branch of Quiroga Garza family. To this end, we will base our analysis on two main points: the genealogy and heritage, essential mainstays to understand the origin and socio-economic development of its members. Our aim is to provide a small contribution to the understanding of this social group in the rural area of Ourense and, by extension, in the inland Galicia.
\end{abstract}

KEY WORDS: Nobility, genealogy, economy, chaplaincy, pious work. 
Recibido/Received: 12/05/2014

Aceptado/Accepted: 03/09/2014

\section{INTRODUCCIÓN Y OBJETIVOS}

a baja nobleza gallega, a la que algunos autores identifican con la $f$ -
dalguía $^{1}$, es el grupo social intermediario por excelencia de la Galicia
moderna $^{2}$. Surgida a la sombra de la vieja nobleza medieval y mediante

1 El término "hidalguía" alude, en propiedad, al concepto o situación jurídica que engloba a todo el conjunto del estamento privilegiado — la nobleza-y, por consiguiente, utilizarlo sólo para identificar a una parte determinada — la menos encumbrada — de la misma resulta formalmente erróneo: jurídicamente, hidalgos y nobles eran análogos, pues los hidalgos eran los nobles y los nobles eran los hidalgos. Ello no obsta para que se reconozcan las grandes desigualdades — no jurídicas — que se daban dentro de este grupo en cuanto a riqueza, poder y posición o reconocimiento social; de ahí, la distinción comúnmente aceptada entre alta, media o baja nobleza, o entre nobleza titulada, nobleza corporativa o simple hidalguía (los primeros exhibían su merced o título del reino, los segundos su pertenencia a órdenes y corporaciones con prueba, y los últimos sólo a su condición de sangre por línea de varón). Esto mismo, aunque con un sentido diferente —en relación sólo con el reconocimiento social y jurídico (antigüedad y notoriedad) y no en cuanto al privilegio inherente-, tenía también su reflejo o correspondencia en las usuales distinciones que por entonces se hacía entre la hidalguía notoria, la hidalguía en propiedad o la hidalguía de privilegio, por ello, no era igual ser conde de Amarante que hidalgo de gotera, aunque ambos individuos perteneciesen formalmente a la hidalguía. (Agradecemos a Eduardo Pardo de Guevara y a Pegerto Saavedra las precisiones al respecto).

2 Este grupo social ha sido objeto de numerosas investigaciones en el marco de la historiografía compostelana, v. Ramón Villares Paz, La propiedad de la tierra en Galicia, 1500-1936, Madrid, Siglo XXI, 1982; Pegerto SaAvedra Fernández, Economía, política y sociedad en Galicia. La provincia de Mondoñedo, 1480-1830, Santiago de Compostela, Consellería da Presidencia, 1985; Luis Domínguez Castro, Viños, viñas e xentes do Ribeiro. Economía e patrimonio familiar, 1810-1952, Vigo, Edicións Xerais, 1992; Paz LeIrós DE La PeÑa, "La casa de Fontefiz", Boletín Auriense, XXIII (1993), págs. 197-237; José Luis Díaz Castroverde-Lodeiro, El señorío de de la Casa de Sonán en su jurisdicción, gobierno y hacienda durante los siglos XVI al XX, Padrón, Novo Século, 1995; Vítor Manuel Migués Rodríguez, "O dominio da Casa de San Fiz de Asma: Evolución e inversión dun dominio fidalgo durante o antigo réxime", Cuadernos de Estudios Gallegos, XLII (1995), págs. 39-67, Vítor Manuel Migués Rodríguez, A fidalguía galega: un breve enxergar histórico a través da Casa de San Fiz de Asma e agregadas, Santiago de Compostela, Tórculo, 1997, Vítor Manuel Migués Rodríguez, As terras, as pousas e os vinculeiros. A fidalguía galega na Época Moderna, Sada, Edicións do Castro, 2002; Antonio Presedo Garazo, Os devanceiros dos pazos: economía e estratexias sociais da pequena fidalguía rural na Galicia interior (ss. XVI-XVIII), Santiago de Compostela, Sotelo Blanco, 1997, Antonio Presedo Gara- 
un largo proceso, adecuadamente constatado por la historiografía, se consolida como una pieza básica en el engranaje político, social y económico. Su extraordinario ascenso desde las capas humildes de la comunidad hasta la posición dominante que detenta en la conclusión del Antiguo Régimen sólo puede explicarse a través de una serie de mecanismos, bien compensados, de promoción política, económica, social y cultural. En este lento desarrollo, los hidalgos se

zo, "A pequena fidalguía rural e a parcería de gando: A Casa da Fraga de San Xiao de Carballo -Friol-, 1680-1800”, Cuadernos de Estudios Gallegos, 109 (1997), págs. 53-78, Antonio Presedo Garazo, "Los ingresos económicos de un hidalgo gallego: rentas y negocios de don Blas María Rubiños (1772-1810)", Investigaciones Históricas. Época moderna y contemporánea, 19 (1999), págs. 11-37, Antonio Presedo Garazo, Dueños y señores de casas, torres y pazos, 1500-1900: (contribución al estudio de la fidalguía gallega), tesis doctoral inédita, Santiago de Compostela, 2001, Antonio Presedo Garazo, "Patrimonio y administración privada en la hidalguía gallega durante el Antiguo Régimen a través del ejemplo de la Casa de Noceda", Estudis d'Història Agraria. Homenatge al Dr. Emili Giralt i Raventós, 17 (2004), págs. 719-728, Antonio Presedo Garazo, A fidalguía galega ante a crise do antigo réxime: (1812-1868), Santa Comba, TresCtres, 2006, Antonio Presedo Garazo, "O clero secular galego de orixe fidalga na Época Moderna: unha poderosa elite local", Compostellanum, LII (2007), p. 651-170, Antonio PresEdo Garazo, A fidalguía galega: estudos sobre a reprodución social dos fidalgos na Galicia Moderna, Santiago de Compostela, Lóstrego, 2008, Antonio Presedo Garazo, "Hidalgos y casas hidalgas en la provincia de Ourense en la Edad Moderna”, en María López Díaz (ed.), Cuadernos Feijonianos de Historia Moderna IV, Santiago de Compostela, Andavira, 2013, págs. 65-105; Isidro García Tato, La Casa de Outarelo en Valdeorras. Formación y desarrollo de su patrimonio (siglos XIV-XX), Madrid, Gráficas Loureiro, 2001; Anastasio Santos Iglesias Blanco, A Casa de Xunqueiras nos séculos XVIII e XIX. Contribución ó estudio das economías fidalgas, Valga, Concello de Valga, 2004, Anastasio Santos Iglesias Blanco, La Casa de Amarante, siglos XVI-XIX, Santiago de Compostela, Universidade de Santiago, 2008; Felipe CASTro Pérez, A Casa de Valladares: formación e evolución do patrimonio dunha familia dominante na Pontevedra do Antigo Réxime, Pontevedra, Deputación Provincial, 2004; Vítor Manuel Migués Rodríguez. y Antonio Presedo garazo, "Los privilegiados", en Isidro Dubert García (coord.), Historia de la Galicia Moderna, Santiago, Universidad de Santiago, 2012, págs. 269-317; José Luis Díaz CAstroverde-Lodeiro, Morgados e xurisdicións na terra e condado de Taboada, séculos XV-XVIII, Guntín, Asociación de Amigos do Mosteiro de Ferreira de Pallares, 2012; Carlos Andrés González Paz (ed.), El Pazo de Tovar: espacios, perspectivas, tiempos, Santiago de Compostela, CSIC, 2012 (Col. Monografías de "Cuadernos de Estudios Gallegos", 12); Iago Rodríguez PalmeIro, "La fidalguía en el interior de la provincia de Lugo. Siglos XVI-XIX”, en Eliseo Serrano Martín (coord.), De la tierra al cielo. Líneas recientes de investigación en historia moderna, Madrid, CSIC, págs. 839-856, Iago RodríGuEz PALMEIRo, "La vida cotidiana de la fidalguía gallega en el interior de la provincia de Lugo. Las casas de Virigo (Navia de Suarna), Hermida y Moreiras (Quiroga). Siglos XVIII y XIX”, en María José Pérez Álvarez, Laureano Manuel Rubio Pérez, Alfredo Martín García (eds.); Francisco Fernández Izquierdo (col.), Campo y campesinos en la España Moderna. Culturas políticas en el mundo hispano, vol. II, León, Fundación Española de Historia Moderna, págs. 1497-1505, Iago Rodríguez PalmeIro, "Fidalgos gallegos en el ocaso de la modernidad. Apuntes de su patrimonio a través de los inventarios de la Casa-Torre de Basille (Baralla) y la Casa de Candendo (Leiro). Siglos XVIII-XIX", [en prensa]; Isolina Rionegro FARIÑA, "Una familia de poder de la élite orensana: los Boán”, en María López Díaz (ed.), Cuadernos Feijonianos...op. cit., págs. 107-127. 
convierten en el paradigma de movilidad de una sociedad considerada tradicionalmente como inmovilista.

Al tratarse de una investigación en curso, hemos centrado nuestro análisis en dos puntos esenciales: la genealogía y el patrimonio, a la espera de poder extender el mismo a las estrategias sociales y la vida cotidiana. A tal efecto, describiremos, en primer lugar, la evolución genealógica familiar, apoyada en los datos que poseemos para, seguidamente, trazar un esbozo de su expansión patrimonial, deteniéndonos en las políticas de cada uno de los señores. Todo ello nos permitirá comprender mejor el crecimiento social y económico de estos hidalgos orensanos, humildes en un principio, pero que alcanzan un relevante desarrollo merced al mercado de la tierra y el comercio del vino.

\section{FUENTES Y METODOLOGÍA}

El fondo del que nos hemos servido en este trabajo se encuentra depositado en el Arquivo Histórico Universitario de Santiago (ARG), en su sección de Archivos Familiares. Consta de cinco mazos de documentación que albergan escrituras de los siglos XVI, XVII, XVIII y XIX, distribuidas atendiendo a su tipología y localización geográfica. Los mazos están divididos a su vez en legajos y éstos en números, que pueden contener uno o varios documentos. En el siguiente cuadro (Tabla 1), reflejamos la división cuantitativa y cualitativa del archivo estudiado.

Tabla 1. Organización del Archivo de la Casa de Candendo

\begin{tabular}{|c|c|c|c|c|}
\hline Mazos & Legajos & Números & Documentos & Tipologías \\
\hline $1^{0}$ & 3 & 47 & 57 & $\begin{array}{c}\text { Documentación familiar y patrimonial } \\
\text { (capilla) }\end{array}$ \\
\hline $2^{\circ}$ & 3 & 20 & 18 & \begin{tabular}{c} 
Documentación económica \\
\hline $3^{\circ}$
\end{tabular} \\
\hline $4^{\circ}$ & 9 & 7 & 101 & $\begin{array}{c}\text { Documentación patrimonial } \\
\text { (parroquias) }\end{array}$ \\
\hline $5^{\circ}$ & 8 & 17 & 48 & Idem. \\
\hline 5 & 26 & 110 & 313 & Idem. \\
\hline
\end{tabular}

Fuente: Archivo Histórico Universitario de Santiago, Archivos Familiares, 78-82.

Esta fuente es el producto de la actividad social y económica que la familia va generando en su evolución histórica. Consta principalmente de escrituras de tipo patrimonial, centradas en esencia en la segunda mitad del siglo XVI y el 
XVII, etapas caracterizadas por una expansión paulatina. El volumen documental decae en el XVIII hasta casi desaparecer en el XIX, debido a que la Casa es asimilada en 1711 por los Quiroga Taboada, y pasa a formar parte de un disperso patrimonio, distribuido por las provincias de Pontevedra, Ourense y Lugo.

Al contrario de lo que suele suceder en los archivos familiares ${ }^{3}$, el que aquí nos ocupa muestra un elevado grado de organización, construida en base a voluminosos conjuntos que reúnen las escrituras con una relativa ordenación cronológica y tipológica. Además, los cuidados dispensados en el Arquivo Histórico Universitario de Santiago han conseguido que la documentación llegue hasta nosotros en óptimas condiciones de conservación. Ello no impide que el fondo se encuentre incompleto, máxime cuando nos detenemos a analizar la documentación familiar, prácticamente inexistente después del año 1700. Este déficit arroja una serie de dudas en la sucesión que es preciso rellenar con el apoyo de otros fondos, ya sean documentales o bibliográficos.

Así pues, hemos empleado registros depositados en el Archivo do Reino de Galicia (ARG), fundamentalmente pleitos que sostienen los miembros de la familia con otros hidalgos, campesinos o contra el monasterio de San Clodio do Ribeiro de Avia, principal poder económico del entorno del solar. Amén de estos, hemos recurrido a varios pleitos por herencia conservados en el Archivo de la Real Chancillería de Valladolid (ARChV), con el ánimo de dilucidar el origen de los Quiroga Taboada, familia en la que desembocará, en último término, el patrimonio de la Casa de Candendo.

\section{Genealogía de la CAsa de CAndendo 4}

El 20 de noviembre de 1555, en los profundos valles vitícolas del Ribeiro de Avia, Gonzalo do Candendo 5 , hidalgo natural de la parroquia de San Miguel de Lebosende, hacía redactar su testamento ante el escribano Rodrigo Pérez ${ }^{6}$. En él estipulaba como sus únicos herederos a sus hijos Pedro González y Sabina Gon-

\footnotetext{
3 Recientemente, hemos efectuado una revisión historiográfica de los trabajos del ámbito galaico que se basan en esta fuente, v. Iago Rodríguez Palmeiro, "Los archivos familiares y la historia rural. Revisión historiográfica y perspectivas de futuro" [en prensa].

4 Ver Anexo I: Árbol genealógico de la Casa de Candendo, (ss. XVI-XVIII)

5 Las fuentes no atestiguan su filiación, aunque posiblemente fuese hijo de Lopo do Candendo y Leonor de Alves, pareja que conocemos merced a una escritura de foro otorgada por el monasterio de San Clodio do Ribeiro de Avia en 1506. Arquivo Histórico Universitario de Santiago, (en adelante AHUS), Archivos Familiares, 80, leg. 1, núm. 1, doc. 1. El complemento toponímico Candendo está vinculado al lugar del mismo nombre, en la feligresía de San Miguel de Lebosende, para más información, v. Frutos Fernández González, O padrón de San Clodio de 1580: estudio histórico e onomástico, Santiago de Compostela, Asociación Galega de Onomástica, 2008, pág. 118.

6 AHUS, Archivos Familiares, 78, leg. 1, núm. 1.
} 
zález, partiendo su patrimonio de forma equitativa entre ambos, y dejándolos a la tutela de de Margarita Fernández ${ }^{7}$, su esposa y madre de los retoños. De igual manera, y para costear su sepultura, dejó a la obra de la iglesia un cañado de vino blanco y al monasterio de San Clodio, un moyo de la misma especie.

Pedro González de Candendo será el verdadero artífice de la expansión de esta familia. Su figura resalta en la historia genealógica, como responsable de la fundación de una capellanía y vínculo en la iglesia de Lebosende, de quien su nieto sería el primer patrón. A pesar de la extensa documentación patrimonial que legó, no hemos podido constatar el nombre ni la procedencia de su cónyuge, pero sí el de su único retoño, Pedro Alonso de Chantada ${ }^{8}$. En su amplio testamento pidió ser enterrado en la capilla de Nuestra Señora del Rosario en San Miguel de Lebosende? .

Pedro Alonso desposó a María González, cuya filiación nos es desconocida. Los escasos documentos que sobre él han quedado demuestran que llevó a cabo una defensa legal de la herencia y bienes que su hijo había recibido como patrón inicial de la capellanía. Primero en la Real Audiencia de Coruña, en cuyo lugar se ejecutó el embargo de los haberes del mencionado Pedro en 1611, por iniciativa de Mateo Álvarez de Bustamante, alcalde mayor del Reino de Galicia, bajo las acusaciones de haber practicado usura; y luego en la Chancillería de Valladolid, donde en 1612 se revocó esta sentencia y dichas posesiones fueron reintegradas ${ }^{10}$. La decisión fue apelada por el fiscal pero se confirmó el 30 de octubre y fue expedida Real Carta Ejecutoria para verificarla ${ }^{11}$.

Así pues, don Andrés Alonso de Chantada, hijo de Pedro Alonso y nieto de Pedro González, se instituyó como primer patrono de la capilla de la Virgen del Rosario en Lebosende y señor de la Casa de Candendo. Con vistas a acrecentar su posición social, entabló matrimonio con la hidalga doña María Pardo Rivadeneira, hermana del regidor de la ciudad de Orense don Juan Pardo de Ulloa

\footnotetext{
7 Desconocemos su ascendencia, aunque su marido desgrana la sencilla dote que aportó al matrimonio: 8 cavaduras de viña en distintos lugares de Lebosende, una cuba de vino, un pote y una caldera de cobre nuevos, más un arca con 12 sábanas de lienzo en su interior. Ibídem.

8 Frutos Fernández indica, en su estudio onomástico, que el complemento "de Chantada" aparece siempre asociado a parientes de los Candendo, v. Frutos Fernández GonZÁlez, O padrón de San Clodio... op. cit., pág. 119.

9 AHUS, Archivos Familiares, 78, leg. 1, núm. 6. Más adelante, nos detendremos en este importante documento.

10 Ibídem, núm. 7. Una copia del pleito se halla custodiada en el Archivo de la Real Chancillería, v. Archivo de la Real Chancillería de Valladolid (en adelante ARChV), Pleitos civiles, Pérez Alonso (F), caja 1862, 1 .

${ }^{11}$ Ibídem, Registro de Ejecutorias, caja 2120, 14.
} 
y Andrade $^{12}$. Este enlace necesitó de aprobación papal en el año 1655 por ser los contrayentes familiares en tercer grado de consanguinidad ${ }^{13}$, pero resultó tremendamente beneficioso para los Candendo, porque les permitió establecer relación con una familia inmersa en el ámbito concejil orensano ${ }^{14}$.

Don Andrés Alonso y doña María Pardo tuvieron cinco vástagos, de los cuales tres fueron varones: don Antonio Candendo, don Andrés (sacerdote), don Benito; y dos mujeres: doña Teresa y doña Jacinta. El padre dejó estipulado en sus últimas voluntades (1655) que la madre debía efectuar una mejora de $3^{\circ} \mathrm{y}$ $5^{\mathrm{o}}$ sobre uno de los hijos ${ }^{15}$. Ésta, por su testamento de 1670, eligió a don Benito como receptor, aunque la sucesión de la capellanía recayó en don Antonio, el primogénito ${ }^{16}$. En otra escritura, doña María hace una donación a don Andrés para que pudiese ordenarse, con bienes por valor de 1800 ducados ${ }^{17}$. Sus dos hijas contrajeron matrimonio, una con Pedro de Rivera, de quien tuvo por descendencia a una niña llamada Benita Rivera; y la otra con Lorenzo de Noboa, con quien engendró dos niños: don Juan y doña María.

Don Andrés, clérigo, testa en 1710 y funda una capilla dedicada a la Virgen del Rosario, designando como heredero al hijo de su sobrina doña Benita Rivera, que a la sazón está casada con José Benavides Quiroga. Además agrega una porción de renta a la capilla creada por Pedro González de Candendo ${ }^{18}$. Este testamento será modificado por un codicilo de 1711 en el cual se estipula que

\footnotetext{
12 En relación a este enlace existen dos documentos de dote fechados en 1619 y 1629, respectivamente. En el primero, don Juan estipula como dote para su hermana la legítima más 1000 ducados de a 11 reales y don Andrés, contrayente, fija aquellos bienes muebles y raíces que tuviere al momento de su fallecimiento, siempre y cuando hubiere descendencia. En el segundo contrato, don Juan promete la misma dote y don Andrés estipula como tal la décima parte de todos sus bienes con las mismas condiciones. El primer documento se halla en Archivo del Reino de Galicia (en adelante ARG), Real Audiencia, C5574-25-; y el segundo en AHUS, Archivos Familiares, 78, leg. 1, núm. 8. 13 Ibídem, núm. 10.

${ }^{14}$ Don Juan Pardo obtuvo la regiduría mediante provisión del obispo y tomó posesión del cargo el 16 de octubre de 1614. Al respecto, me remito a María López Díaz, Jurisdicción e Instituciones locales de la Galicia meridional (XVI-XVIII), Vigo, Servizo de Publicacións da Universidade de Vigo, 2011, pág. 195.

15 AHUS, Archivos Familiares, 78, leg. 1, núm. 9.

16 Ibídem, núm. 12.

17 Ibídem, núm. 11. La dedicación de los segundones al mundo religioso era una estrategia recurrente de las familias hidalgas, que perseguían con ello no sólo el valor simbólico de contar en sus filas con un pariente eclesiástico, sino reforzar sus patrimonios con las aportaciones de los clérigos en el momento de su muerte. Sobre este particular, v. Antonio Presedo Garazo, "O clero secular galego de orixe fidalga na época moderna: unha poderosa elite local”, Compostellanum, 52 (2007), págs. 651-670.

18 AHUS, Archivos Familiares, 78, leg. 1, núm. 22.
} 
esta renta se entienda adjudicada a la capilla establecida por él, no a la de su abuelo Pedro ${ }^{19}$.

Por su parte, el hermano mejorado, don Benito, cede en 1712, mediante una donación inter vivos todos sus bienes muebles y raíces, censos, rentas, derechos y acciones, a su sobrino nieto don Ignacio Quiroga Taboada ${ }^{20}$, continuador de la línea como veremos más adelante.

La sucesión de don Antonio Candendo no está exenta de litigios. Concretamente, una demanda de su madre doña María puesta contra la misión en posesión de los bienes solicitada por el primero en la Real Audiencia del Reino de Galicia en $1656^{21}$. Ésta reclamaba no haber lugar al disfrute de los bienes mientras no le fuera satisfecha la dote que su hermano le había dejado estipulada para su casamiento con don Andrés Alonso de Chantada y que éste había gastado en la remodelación de la Casa de Candendo; además, solicitaba una pensión alimenticia para ella y sus hijos menores. El tribunal falló a favor de don Antonio, otorgándole la posesión del vínculo y capellanía, a condición de que satisficiese los requerimientos interpuestos por su progenitora.

Así pues, tras estos avatares legales, don Antonio Candendo Pardo Rivadeneira se instituye como señor de la Casa, su capilla y obra pía, en el tercer cuarto del siglo XVII. Poco después, toma estado con doña Ana María Pungín Villamarín, que concibe tres hijos: el capitán don Juan Antonio, doña Benita y doña Micaela. En sus últimas disposiciones, efectuadas en 1685, el padre estipula que si su hijo varón cumple unas determinadas condiciones (alimentar, vestir y dotar correctamente a sus dos hermanas) agregará todos sus bienes al vínculo original, para que su primogénito lo lleve como heredero ${ }^{22}$. $\mathrm{Al}$ margen de su matrimonio, aparece en su testamento una hija natural, de nombre Ana, que profesa como monja en el convento de Santa Clara de Allariz, y a quien deja 12 ducados anuales.

Don Juan Antonio entrega un informe ante el alcalde mayor de la jurisdicción de San Clodio para probar que era el único hijo varón de don Antonio $^{23}$, y sus hermanas le otorgan sendos poderes con el objeto de que cobre las deudas que quedasen pendientes en el testamento de su padre ${ }^{24}$. No obstante, don Juan

\footnotetext{
19 Ibídem, núm. 23.

20 Ibídem, núm. 24.

21 ARG, Real Audiencia, C5574-25-.

22 AHUS, Archivos Familiares, 78, leg. 1, núm. 14. Una copia se encuentra depositada en el Archivo del Reino, v. ARG, Real Audiencia, C5574-25-.

23 AHUS, Archivos Familiares, 78, leg. 1, núm. 15.

24 Ibídem, núm. 16.
} 
Antonio, que contrae matrimonio con doña Jacinta Antonia de Aldao ${ }^{25}$, no tiene sucesión legítima ${ }^{26}$, por lo que el vínculo, capellanía y obra pía recaen en doña Benita, casada con don Diego de Quiroga Taboada, señor de los cotos de Toiriz (Pantón) y Abuíme (Saviñao) y a la sazón juez de las jurisdicciones de Deza y Lalín, sucesor de una rama secundaria de la familia Garza Quiroga ${ }^{27}$, poseedora entre otros, del pazo de Tor.

La dote que doña Benita llevó aparejada para el matrimonio en 1687 estaba conformada por 2.200 ducados aportados por su hermano y 1.500 por don Diego, este documento provocó a partir de 1693 un largo pleito en el Tribunal Militar de la Capitanía de Coruña, entre don Juan Antonio Candendo y don Diego Quiroga, debido a que el primero le debía a esas alturas más de 25.000 reales y 80 cañados de vino. Se llegó a ordenar el embargo y transacción de una porción de los bienes de don Juan, que tuvo que recurrir a la venta de algunos censos que su antepasado don Pedro había agregado ${ }^{28}$.

De hecho, la situación económica de la Casa y la capilla se había deteriorado de manera significativa, lo que llevó al incumplimiento de las misas y las dotaciones $^{29}$. En los postreros años del siglo XVII, concretamente en 1698, don Juan llegó a un acuerdo con el obispado para reducir las cargas de la capellanía, que descendieron a 1500 reales anuales. Con respecto a los atrasos, se dispuso que quedasen compensados con los perfectos practicados a las casas y bodegas anejas al lugar do Candendo, perpetuamente unidas a la fundación ${ }^{30}$.

Este es un momento clave en la historia de la Casa de Candendo, porque significa su absorción por la familia de don Diego, con la que perderá toda autonomía y pasará a formar parte del patrimonio de los Quiroga Taboada. El traspaso

25 Doña Jacinta recibió una dote de su hermano el sargento don Baltasar José Fernández de Aldao, consistente en una serie de alhajas y mobiliario, más 70 doblones de a ocho. Llegado el momento, se ve obligada a recurrir a su dote para enfrentar las numerosas deudas de su marido, a cambio, éste le cede en 1703 una serie de bienes en compensación. Ibídem, núm. 19.

26 Tiene una hija natural llamada doña Ana María Candendo, a quien otorga un foro de diversas propiedades en el lugar de Ibedo, San Andrés de Vieite, el año de 1708. Ibídem, 81, leg. 1, núm. 1, doc. 17.

27 Para más información acerca de la genealogía de los Garza Quiroga, v. Eduardo PARDo DE GUEVARA Y VALDÉS, De linajes, parentelas y grupos de poder: aportaciones a la historia social de la nobleza bajomedieval gallega, Madrid, Fundación Cultural de la Nobleza Española, 2012, págs. 323-362; Benjamín de Prado Díaz, El linaje de la Casa de Tor, introducción y estudio de Eduardo Pardo de Guevara y Valdés, Lugo, Deputación Provincial, 2007.

28 AHUS, Archivos Familiares, 78, leg. 1, núm. 19.

29 Es traza común en este tipo de fundaciones, que tienden a desaparecer a lo largo del tiempo, por la merma de las rentas y la desidia de los herederos. Al respecto, v. Domingo Luis GonzÁLEZ Lopo, Mentalidades religiosas en la Galicia del Barroco, Santiago, Xunta de Galicia, 2002, págs. 625-681.

30 AHUS, Archivos Familiares, 78, leg. 1, núm. 18. 
se ve confirmado por un convenio fechado en 1711 entre don Diego Quiroga y su hijo don Ignacio con doña Jacinta Antonia, por el que éstos se obligaron a dar a aquélla 10.000 reales de vellón en seis plazos, más cinco moyos de vino tinto de renta durante su vida. Además, se comprometieron a cargar con los funerales de don Juan Antonio, desempeñar la plata empeñada del mayorazgo, y pagar los lutos de la señora. A cambio, doña Jacinta se apartó de cualquiera acción o pretensión por razón de dote y gananciales y herencia de su marido, y los cedió en dichos don Diego de Quiroga y su hijo ${ }^{31}$.

\section{Los PATRIMONios de la hidalguía gallega. MeCANismos de CONSTITUCIÓN Y AFIANZAMIENTO DE UNA ÉLITE RURAL RENTISTA}

Para entender la relevancia socioeconómica de la hidalguía gallega en el Antiguo Régimen es preciso estudiar los procesos característicos a partir de los cuales se construyen sus dominios ${ }^{32}$. Se debe, asimismo, analizar bajo qué circunstancias éstos se producen, y qué operaciones destacadas llevan a cabo para situarse en un breve espacio de tiempo en la cúspide de la sociedad rural. Como ha apuntado Ramón Villares, la formación de los patrimonios hidalgos en Galicia se hace a partir de dos vías principales: la obtención de forales, fundamentalmente eclesiásticos, cuyo dominio útil es usufructuado por los hidalgos (llegando incluso a sustituir su titularidad) y la compra de tierras no pertenecientes a estos forales, propiedad de campesinos que se ven en la obligación de venderlas, bien por endeudamiento, o por presión de los inversores ${ }^{33}$.

\footnotetext{
31 Ibídem, núm. 21.

32 Antonio Presedo Garazo, Os devanceiros... op. cit., pág. 41.

33 Ramón Villares Paz, La propiedad de la tierra... op cit., págs. 80-91; Antonio Eiras Roel, "Régimen subforal e hidalguía intermediaria". Prólogo al libro de Carmen Quintáns Vázquez, El dominio de San Martín Pinario ante la Desamortización, Santiago de Compostela, Secretariado de Publicaciones de la Universidad, 1972, págs. 10-12; Pegerto SaAvedra Fernández, Economía, política y sociedad... op. cit., págs. 437-438. Este último autor incidió en la importancia de las adquisiciones de tierras por parte de grupos sociales emergentes en la Galicia moderna, enmarcadas en contextos de recesiones económicas que afectaban esencialmente al campesinado, sumiéndolo en el endeudamiento, v. Pegerto SaAvedra Fernández, "Un aspecto de las crisis de subsistencias en la Galicia del Antiguo Régimen: las ventas de tierra, en Antonio Eiras Roel et al., La historia social de Galicia en sus fuentes de protocolo, Santiago de Compostela, Servicio de Publicaciones, 1981, págs. 181-204. Vítor Migués y Antonio Presedo han demostrado la enorme relevancia de las adquisiciones de tierras y rentas, amén de la reproducción social, en el incremento patrimonial de las casas hidalgas gallegas, v. Antonio Presedo Garazo, Os devanceiros... op. cit., págs. 46-64, Antonio Presedo Garazo, A fidalguía galega ... op. cit.; Vítor Manuel Migués Rodríguez, As terras, as pousas... op. cit., págs. 171-190, Vítor Manuel MiguÉs RodRíGUEz, "La intermediación foral sobre los patrimonios eclesiásticos: la superación de una hipérbole historiográfica", en María López Díaz (ed.), Estudios en homenaje al profesor José M. Pérez García, vol. 2, Vigo, Servizo de Publicacións da Universidade de Vigo, 2009, págs. 189-206.
} 
Efectivamente, la Casa de Candendo se sirve de las dos estrategias para configurar sus propiedades. Por un lado, recurre a la fórmula foral, obteniendo generosas sumas de bienes del dominio directo del monasterio de San $\mathrm{Clodio}^{34}$, y por otro, participa del mercado de la tierra mediante compras localizadas en su área que consolidan inicialmente su posición económica en la zona, para ampliarla con el discurrir del tiempo, a lugares diferentes. Esta planificación le permite tejer una red de influencias que se asentarán sobre la práctica crediticia de los señores de Candendo ${ }^{35}$. La escasez de escrituras dotales ha impedido, por el momento, determinar qué cantidad de posesiones entraron a formar parte del patrimonio como resultado de las políticas matrimoniales.

\section{Los orígenes de la Casa de Candendo en la segunda mitad del siglo XVI}

El documento más antiguo que alberga el archivo es un foro efectuado el 28 de febrero de 1506 por el abad y los monjes del monasterio de San Clodio a Lopo do Candendo y Leonor de Alves. Esta cesión supone la constitución de la base patrimonial de la Casa, en tanto el cenobio entrega el dominio útil del lugar do Candendo — con su casa y corral, viñas y cortiñas, árboles, entradas y salidas a montes, entre otros bienes - por la pensión de un capón y dos maravedíes viejos, más el quinto de las viñas y diversas retribuciones ${ }^{36}$.

Si bien no vuelven a reparar en Lopo do Candendo y Leonor de Alves, las fuentes aluden a dos protagonistas iniciales: la pareja formada por Gonzalo do Candendo (posible hijo de los anteriores) y Margarita Fernández, naturales del lugar do Candendo. En un primer momento y mediante tres escrituras de foro elaboradas en los años 1544,1548 y $1553^{37}$, consiguen el control de varias viñas

${ }_{34}$ La documentación medieval de este cenobio ha sido analizada por Manuel Lucas Álvarez y Pedro Lucas Domínguez, v. Manuel Lucas Álvarez y Pedro Lucas Domínguez, El monasterio de San Clodio do Ribeiro en la edad media: estudio y documentos, Sada, Edicións do Castro, 1996. Ana Goy Diz también realizó un estudio sobre el mismo, v. Ana Goy Diz, O Mosteiro de San Clodio de Leiro, A Coruña, Fundación Caixa Galicia, 2005.

${ }^{35}$ La bonanza económica de ciertos hidalgos les permitía desviar destacadas cantidades de dinero para la concesión de créditos a campesinos endeudados u otros señores cuya fortuna había sido más adversa, v. Antonio PRESEDo GaRAzo, "La capacidad crediticia de la nobleza provincial del Reino de Galicia durante los siglos XVI-XVIII", Lucensia, 29 (2004), págs. 231-244.

36 AHUS, Archivos Familiares, 80, leg. 1, núm. 1, doc. 1. Aunque nuestro testimonio más antiguo se remonta a los inicios del siglo XVI, el libro citado en la nota 33 recoge un foro del monasterio de San Clodio a los escuderos García Carballo y Juan Bezerra. En esta escritura, fechada en 1466, los monjes aforan unos lugares en Leiro, entre los cuales se indica "una leyra de viña que jaz en Veiga de Campo, segundo que a traje a jur e a mao Lopo de Candendo e Aluaro Guerra [...]", así pues, Lopo do Candendo ya aparece como llevador de tierras del cenobio cisterciense en el tercer cuarto del siglo XV. Al respecto, v. Manuel Lucas Álvarez y Pedro Lucas Domínguez, El monasterio de San Clodio... op. cit., pág. 696.

${ }^{37}$ AHUS, Archivos Familiares, 80, leg. 1, núm. 1, docs. 2 y 3. Ibídem, núm. 2, doc. 1. 
y un monte del directo dominio de los monasterios de San Clodio y Acibeiro, en distintas zonas de la feligresía de San Miguel de Lebosende.

En las décadas siguientes los aludidos cónyuges consuman una serie de 17 transacciones sobre propiedades conformadas por bienes raíces y rentas de labriegos, en su mayor parte libres de cargas, a excepción del diezmo, además de algunos lugares.

En el Mapa 1 verificamos mejor el proceso. El área original donde se asentaba la Casa de Candendo (lugar del mismo nombre, San Miguel de Lebosende, Leiro) y donde se efectuaron la mayoría de las compras de los primeros años figura en color negro. El gris oscuro indica las áreas de expansión (O Irixo y Avión) en esta etapa.

Mapa 1. Ubicación original de la Casa de Candendo y áreas de expansión patrimonial en la provincia de Ourense (1545-1588)

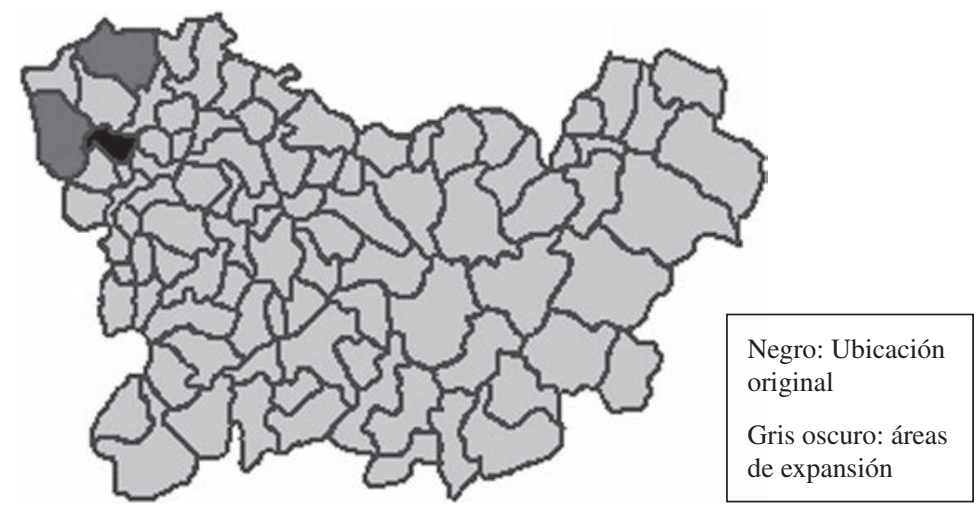

Fuente: Archivo Histórico Universitario de Santiago, Archivos Familiares, 78-82.

En el Gráfico 1 podemos comprobar la evolución de estos movimientos: mientras que en la fase inicial las actuaciones alcanzan un montante de $76 \mathrm{du}$ cados consignados para un total de tres compras, la segunda se caracteriza por una ligera rebaja en el gasto, que decae hasta los 62 repartidos en siete. En la tercera fase se lleva a cabo una inversión de 148 en cinco, y en la cuarta sólo se efectúan dos compras por un valor de 25. La suma utilizada alcanza los 311 ducados, una cifra escasa que se explica, en parte, por la coincidencia temporal con la actividad del hijo de la pareja, Pedro González de Candendo, iniciada ya a la altura de 1559 . 
Gráfico 1. Compras de Gonzalo do Candendo y Margarita Fernández, en ducados $(1545-1588)^{38}$

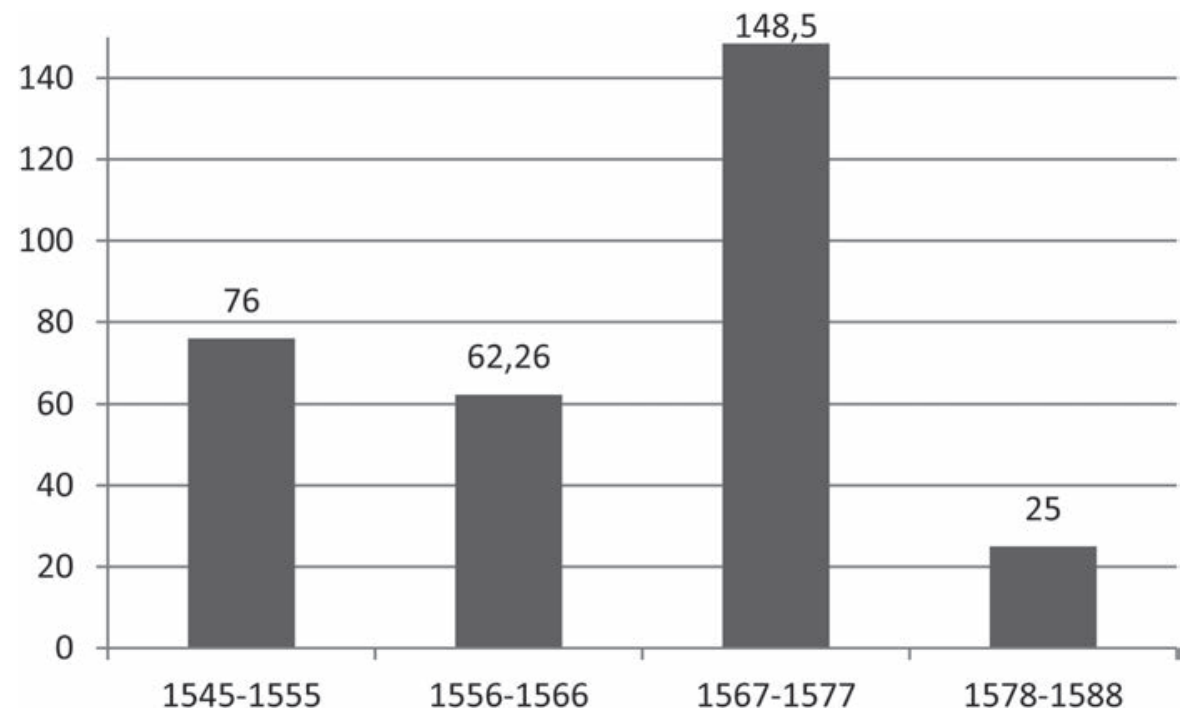

Fuente: Archivo Histórico Universitario de Santiago, Archivos Familiares, 78-82.

En lo que atañe a la estructura de estas captaciones, se distribuye en la forma que indica el Gráfico 2. Observamos que la tendencia durante la primera década es a la atracción de rentas, consistentes en pequeñas cantidades de vino, centeno y lino en Santa María de Lamas, San Tomé de Serantes y Santa María de Gomariz. A partir de 1556 los objetivos se diversifican, incluyendo determinadas viñas y rentas de centeno en las mismas feligresías, además de la mitad de dos lugares (A Ermida y Nabás) en Santa María do Campo y Santa Mariña de Cidá, con sus rendimientos correspondientes. En el período siguiente, Margarita consigue la parte de una herencia sobre un pardiñeiro y un resío en el lugar de Leiro, parroquia de San Pedro del mismo nombre, además de algunas viñas y tierras labradías en el lugar de Paredes, perteneciente a San Tomé de Serantes. El último decenio presenta dos intervenciones testimoniales sobre ciertas rentas en Santa María de Lamas y una pieza de labor en el lugar de Beresmo, San Xusto de Avión.

\footnotetext{
38 A partir de 1567 las compras las realiza Margarita Fernández como viuda.
} 
Gráfico 2. Composición de las compras realizadas por Gonzalo do Candendo y Margarita Fernández, en ducados (1545-1588) ${ }^{39}$

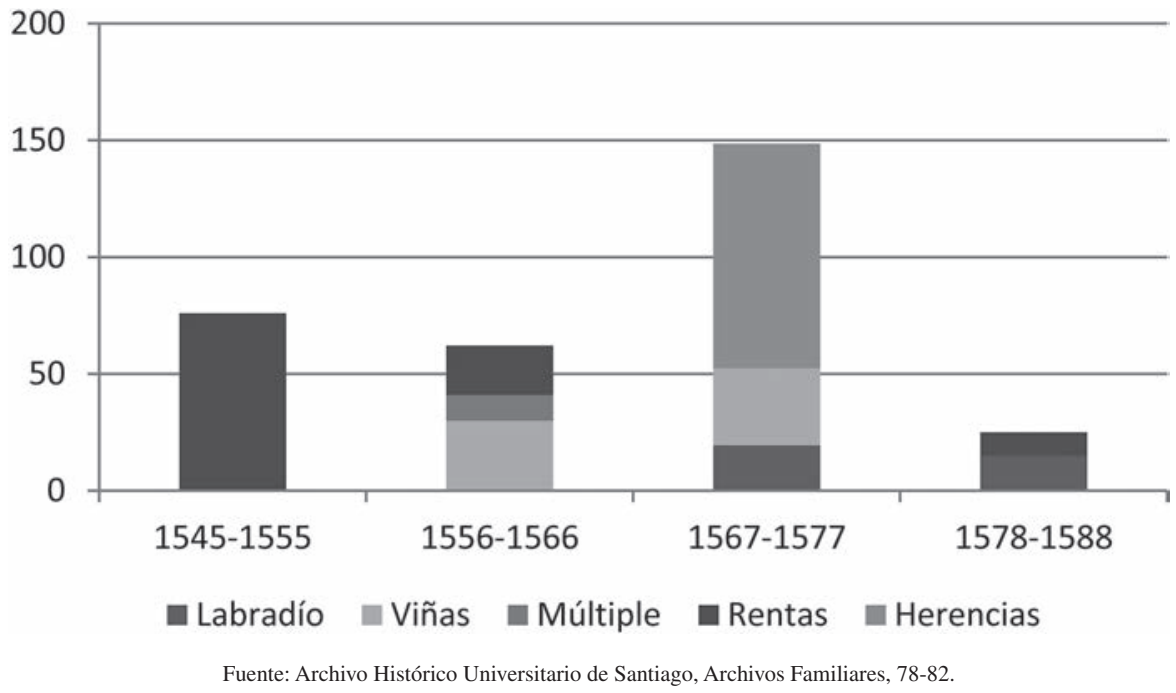

Así pues, los pasos preliminares de la familia Candendo van encaminados hacia la consolidación de un pequeño patrimonio en las feligresías adyacentes a Santa María de Lebosende. En un primer momento se aseguran el control de algunas viñas y un monte, dependientes de dos instituciones eclesiásticas. Posteriormente, comienzan a mostrar interés en la asunción de rentas y determinados bienes raíces (viñas y labradíos), propiedad de labriegos del entorno. Aún así, el reducido dispendio y la dependencia de los forales, indican que estamos todavía en una fase embrionaria de la expansión y que la tendencia de la misma es muy local, centrada en lugares conocidos que garanticen la rentabilidad y minimicen los riesgos.

\footnotetext{
39 Debido a la multiplicidad de medidas que revelan las fuentes, o a su ausencia, no ha sido posible homogeneizarlas en una sola unidad, lo que hubiese dado una idea más precisa de la superficie y/o cantidad obtenida en esta primera fase. Por ello, hemos preferido evaluar el proceso en función del dinero destinado a cada tipo de bien, tomando como base los valores que aporta Elena García Guerra para ducados, reales y maravedíes en la época que nos concierne, v. Elena García Guerra, "Moneda en España en los siglos XVI-XVII", en Alfredo Alvar Ezquerra et al., La economía en la España Moderna, Madrid, Istmo, 2006, págs. 201-240.
} 


\section{La etapa de las vinculaciones en el tránsito del siglo XVI al XVII: la actividad expansionista de Pedro González de Candendo.}

Las operaciones que acabamos de analizar comienzan a perfilar el patrimonio del solar, pero, a la hora de hacer referencia a su extensión, es imprescindible detenernos en la figura del exponente más notable de la familia: don Pedro González de Candendo ${ }^{40}$. Su nombre aparece en gran cantidad de escrituras, reflejo de su intensa actividad comercial en pro del crecimiento económico: compras, permutas, censos, obligaciones... pergaminos donde se suceden contratos sobre casas, viñas, labradíos, montes, prados, hórreos, molinos...etc., con la particularidad de se trata siempre de bienes raíces, y no de rentas. Esta heterogeneidad de intervenciones contrasta con la práctica ausencia de foros, puesto que tan sólo recibe uno por parte del rector de la iglesia de Santa María de Lamas, que recompensó así, su apoyo en un pleito contra el obispado de Ourense ${ }^{41}$.

Gráfico 3. Compras de Pedro González do Candendo, en ducados (1559-1601)

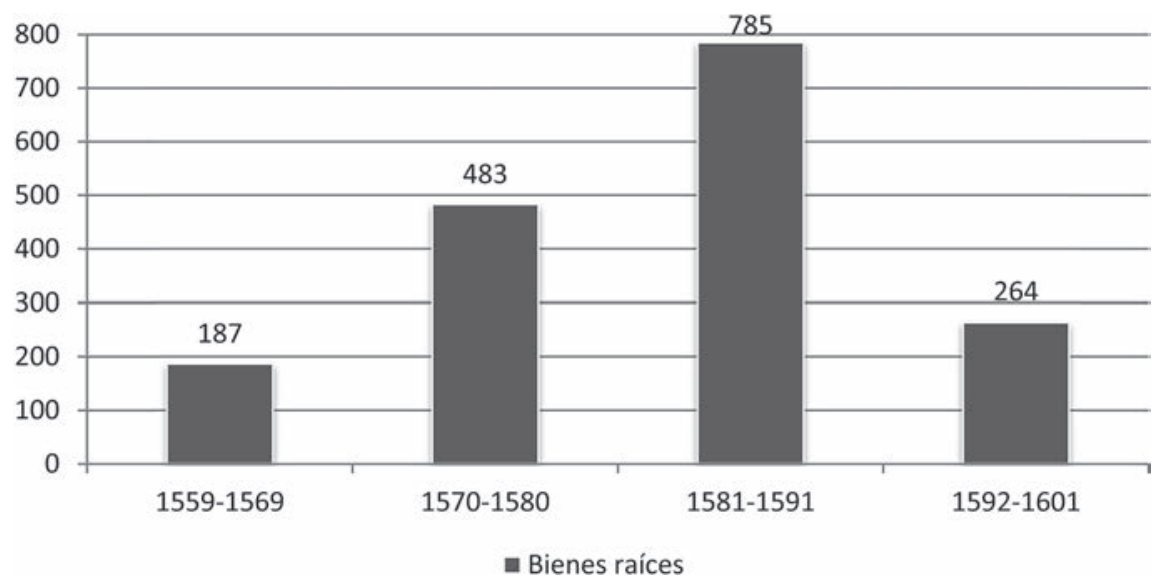

Fuente: Archivo Histórico Universitario de Santiago, Archivos Familiares, 78-82

\footnotetext{
40 El origen y expansión de las casas hidalgas se basa con frecuencia en la actividad intensa de uno o más señores que ejecutan políticas de inversión concentradas en un breve espacio temporal. Las adquisiciones hechas suelen ser vinculadas para proporcionar a la familia una base patrimonial segura sobre la que asentarse. Como indican los profesores Migués y Presedo: "Es traza común en todos ellos la posesión de una personalidad audaz e hiperactiva que, amparada en un ciclo económico expansivo, les lleva a plantear estrategias de choque que se traducen en procesos fulgurantes de acaparamiento de derechos patrimoniales, fundamentalmente sobre la tierra, y en especial rentas". Vítor Manuel Migués Rodríguez y Antonio Presedo Garazo, "Los privilegiados..." cap. cit., pág. 274.

${ }^{41}$ Se trata del foro del lugar del Iglesario en Santa María de Lamas, a cambio de 3 moyos de vino blanco. AHUS, Archivos Familiares, 81, leg. 3, núm. 2, doc. 1.
} 
Su política de compras arroja una cifra de 64 transacciones (descontando permutas o cesiones), con inicio en el año 1559 y final en el 1601, que evidencian una inversión de 1719 ducados (18.909 reales) ${ }^{42}$, y una media anual de 450. En la primera década, realiza un gasto de 187 ducados repartidos en trece operaciones, cifra que aumenta en el período 1570-1580, hasta los 483 divididos en veintitrés. El tercer tramo supone el apogeo de las compras de nuestro hidalgo, hasta el punto de destinar 785, distribuidos en tan sólo diez movimientos. Este ritmo se desacelera a partir del año 1592, donde desciende a 264, asignados a once transacciones.

Como reflejamos en el Mapa 2, estas actividades tienen lugar en un primer momento en la feligresía de San Miguel de Lebosende y el actual ayuntamiento de Leiro (en negro), pero conforme avanza el tiempo, se extienden por buena parte de la comarca del Ribeiro (ayuntamientos de Cenlle y Avión ${ }^{43}$ ) y, en menor medida, de O Carballiño (ayuntamientos de Boborás y O Irixo ${ }^{44}$ ), dichas zonas se resaltan en gris oscuro.

Mapa 2. Localización de las compras de Pedro

González do Candendo (1559-1601)

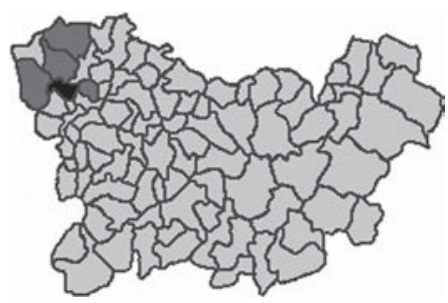

Negro: Ubicación original

Gris oscuro: áreas de expansión

Fuente: Archivo Histórico Universitario de Santiago, Archivos Familiares, 78-82.

42 Este nivel de inversión se coloca por debajo de otros casos documentados, en su mayor parte de la nobleza titulada. Don Pedro Bermúdez de Castro, señor de Montaos, empleó 17.429 reales en 55 contratos, v. Antonio Presedo Garazo, Nobleza y régimen señorial en Galicia: la Casa de Montaos en los siglos XVI y XVII, Santiago de Compostela, USC Editora Académica, 2012, págs. 80-81; Don Diego de Ulloa Ribadeneira de Noceda, realizó 158 compras por un total de 23.154 rs., v. Antonio Presedo Garazo, "Patrimonio y administración..." art. cit., págs. 719-728. Aún así, supera con mucho las cantidades asignadas por distintos hidalgos. Véanse las adquisiciones de Esteban Tenreiro (1757 mrs. en 163) y José Benito Prado Lemos (2163 mrs. en 163), v. Vítor Manuel Migués RodRíGuEz, As terras, as pousas... op. cit., págs. 172-173. Otros ejemplos de menor inversión los tenemos en las operaciones de Gerónimo Gil de Quiroga, de los Quiroga-Armesto, que realizó 78 compras con un desembolso de 7761,50 rs. o las de Juan García de Prado Ribadeneira, señor de Vilanova de Dormeá, que emplea 6257 rs. en 13, v. Antonio Presedo Garazo, $O s$ devanceiros... op. cit., págs. 50-62.

${ }_{43}$ Leiro, (parroquias de San Miguel de Lebosende, Santo Adrao de Vieite, San Breixo de Berán, Santa María de Lamas y Santo Tomé de Serantes); Cenlle, (San Lourenzo da Pena); Avión, (Santos Xusto e Pastor de Avión, Santiago de Amiudal y Santa Mariña de Córcores).

${ }^{44}$ San Pedro de Xurenzás y Santa Mariña da Cidá, respectivamente. 
A la luz de los datos reflejados en el Gráfico 4 podemos desgranar la constitución de los bienes descritos en los documentos. En la primera década los intereses se centran en tierras de labor, viñas y montes, además de ciertas edificaciones, como casas y hórreos. Ya en el segundo tramo se observa un aumento importante de las captaciones de viñedos y montes, mientras que los labradíos y construcciones tienen una menor presencia. En el decenio siguiente destaca una compra de diversas heredades en el lugar de Cuñas (San Lourenzo de Pena), por la considerable suma de 600 ducados $^{45}$, además de viñedos y edificios. Los últimos años muestran un descenso del gasto, concentrado esencialmente en tierras de viñedo. Si exceptuamos las posesiones radicadas en San Miguel de Lebosende, en su mayor parte de dominio directo del Monasterio de San Clodio, muchas de las adquisiciones están conformadas por bienes libres de cargas jurisdiccionales, propiedad de pequeños campesinos que se ven obligados a renunciar a ellos por la presión de las deudas ${ }^{46}$.

Gráfico 4. Composición de los bienes raíces adquiridos por

Pedro González de Candendo, en ducados (1559-1601)

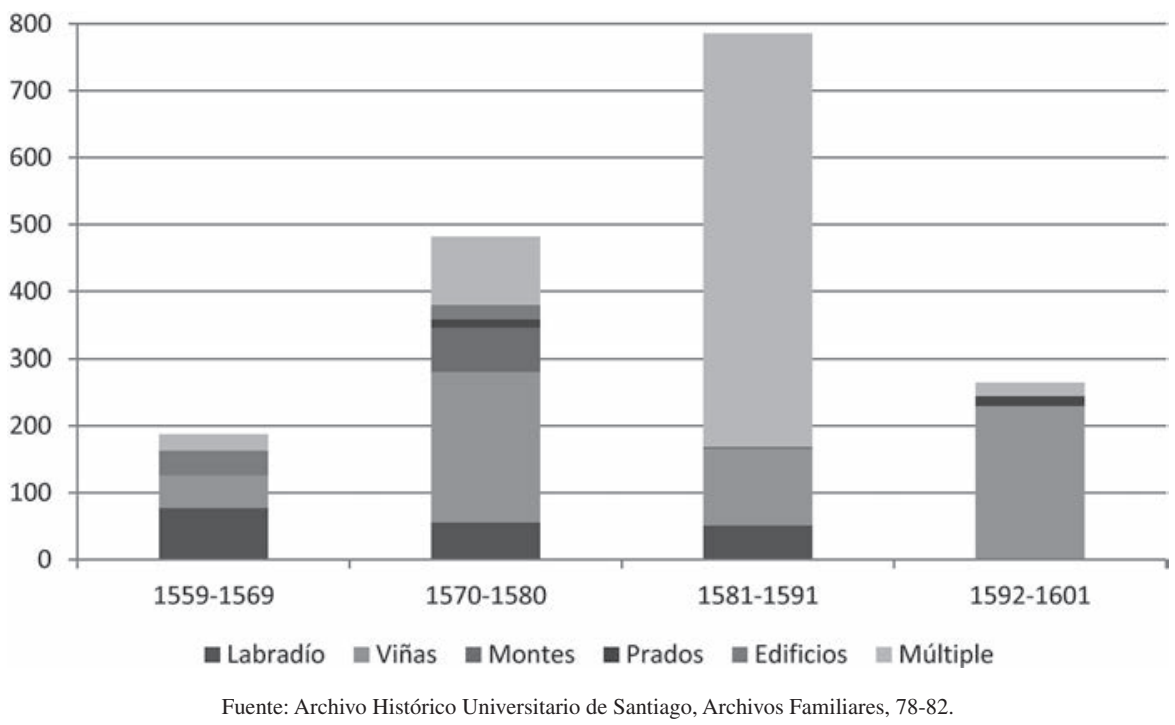

45 AHUS, Archivos Familiares, 81, leg. 5, núm. 1, doc. 3.

46 Sobre el endeudamiento crónico del campesinado en la Edad Moderna, v. Pegerto SAAVEdRA Fernández, La vida cotidiana en la Galicia del Antiguo Régimen, Barcelona, Crítica, 1994, págs. $17-45$. 
Aunque los hidalgos gallegos sabían que el incremento de la hacienda era muy importante, no dejaban de lado la imagen pública, signo de prestigio. Dada su condición de personas notorias de la vecindad, tenían que hacer valer su superioridad a través de una serie de signos culturales que les otorgasen una pátina diferenciadora del entorno. Por ello, nuestro protagonista ordenó levantar en la feligresía de San Miguel de Lebosende, una capilla consignada a la advocación de Nuestra Señora del Rosario, de gran devoción en la zona, para lo cual solicitó consentimiento a los propios feligreses. Éstos accedieron a la obra el 14 de marzo de 1567 , no sin ciertas reticencias ${ }^{47}$.

Poco a poco, la Casa de Candendo se expande, centrada en el acaparamiento de rentas y tierras vinícolas, pero sin obviar el crecimiento jurisdiccional. Así, Pedro González obtiene en 1587, mediante privilegio real, parte de las alcabalas de la ciudad de Ourense (70.000 maravedíes anuales), de manos de los monjes del monasterio de Santa Clara de Valladolid, (quienes las habían heredado a su vez de doña Leonor de Castro, condesa de Ribadavia) ${ }^{48}$, a cambio de 57.647 rs. (1.960.000 maravedíes o 5.241 ducados aprox.). Además, consigue el señorío de Santo Adrao de Vieite, aldea de Cuñas (San Lourenzo da Pena) y la Granja de Vestería de Gomariz, enajenados al monasterio de San Clodio y concedidos por Real Cédula de Felipe II el 12 de febrero de $1591^{49}$.

\footnotetext{
47 Algunos fieles solicitaban un lugar de enterramiento tan bueno como el que cedían para la edificación. AHUS, Archivos Familiares, 78, leg. 2, núm. 1.

48 Ibídem, leg. 3, núm. 2, doc. 2. Gonzalo Fernández ha trabajado la documentación del Condado de Ribadavia, v. Gonzalo Francisco Fernández SuÁrez, La nobleza gallega entre los siglos XIV-XV. Los Sarmiento, condes de Ribadavia, Santiago de Compostela, El Eco Franciscano, 2002. Podemos encontrar un extracto de algunos documentos de doña Leonor en: Gonzalo Francisco Fernández SuÁrez, "Los Condes de Ribadavia durante el reinado de Carlos V", Estudios Mindonienses, 21 (2005), págs. 49-313.

49 El señorío de estos territorios pertenecía al monasterio de San Clodio de Leiro, pero fue transferido al monarca mediante breve del papa Gregorio XIII, a cambio de un privilegio de juro en las alcabalas de Santiago de Compostela. AHUS, Archivos Familiares 81, leg. 1, núm. 2, doc. 1. Las necesidades económicas de la Corona favorecieron la venta de bienes eclesiásticos a lo largo del siglo XVI, autorizadas por diversas disposiciones pontificias. María López Díaz ya refiere la desmembración (y luego la recuperación) de los bienes del monasterio de San Clodio de Leiro en su exhaustivo estudio de este fenómeno en Galicia: María López DíAz, "Alteraciones en el mapa jurisdiccional gallego durante la Edad Moderna: las desmembraciones eclesiásticas del siglo XVI", Estudios mindonienses, 7 (1991), págs. 559-588. Más recientemente y en la misma línea contamos con el estudio de María Ángeles Faya, centrado en el reinado de Felipe II: María Ángeles FaYA Díaz, "Los señoríos eclesiásticos gallegos y la venta de jurisdicciones en tiempos de Felipe II", en José L. Pereira Iglesias y Jesús M. González Beltrán (eds.), Felipe II y su tiempo, Actas de la V Reunión Científica de la Asociación Española de Historia Moderna, Cádiz, Servicio de Publicaciones de la Universidad, 1999, págs. 101-115. A nivel español y de modo general, podemos citar los estudios de Salvador Moxó y OrTiZ DE VILlajos, "La desamortización eclesiástica del siglo XVI", Anuario de historia del derecho español, 31 (1961), págs. 327-362 y Alfonso María GuILARTE ZAPATERo, El régimen señorial en el siglo XVI, Valladolid, Universidad de Valladolid, 1987. En los
} 
En los años siguientes, también mostró interés en la compra de deuda pública, amparado en el contexto económico del momento, por el cual la Corona, necesitada de ingresos para sostener su agresiva política exterior, comenzó a vender juros ${ }^{50}$. De esta forma, el 23 de abril de 1605, adquiere un juro de 83.800 maravedíes anuales por 1.676.050 de principal, cuyos réditos estaban situados sobre las alcabalas de Viana do Bolo, Souto Bermudo, Verín y Pacios de Monterrei ${ }^{51}$. Seguidamente, el 23 de septiembre de 1609 obtiene 37.137 maravedíes a cambio de 1.299.795 de principal, situados en el Coto de San Clodio de la diócesis de Ourense ${ }^{52}$.

Sobre este crecimiento patrimonial y jurisdiccional se basa una parte importante de la estructura económica de la Casa de Candendo, desde que por su testamento, fechado en $1611^{53}$, Pedro González instituyó una capellanía bajo la advocación de Nuestra Señora del Rosario, en la parroquia de Lebosende ${ }^{54}$. Para su cuidado estableció que hubiese siempre tres capellanes, encargados de rezar una misa diaria de forma perpetua, señalándoles 25 ducados anuales pagados por el patrón que correspondiese, con la condición de que ayudasen al rector de la

\footnotetext{
últimos años esta línea de investigación ha seguido avanzando merced a nuevos trabajos: Alberto Marcos Martín, "Enajenaciones por precio del patrimonio regio en los siglos XVI y XVII. Balance historiográfico y perspectivas de análisis", en Roberto J. López et al., Balance de la historiografía modernista: 1973-2001. Actas del VI Coloquio de Metodología Histórica Aplicada (Homenaje al profesor Antonio Eiras Roel), Santiago de Compostela, Xunta de Galicia, 2003, págs. 419-443. Si nos ceñimos al análisis de quiénes son los que compran estos señoríos, v. Enrique Soria Mesa, La venta de señoríos en el Reino de Granada bajo los Austrias, Granada, Universidad, 1995. Para el caso concreto de la venta de jurisdicciones pertenecientes al monasterio de San Clodio, v. Frutos Fernández GonZález, O padrón de San Clodio...op. cit., págs. 35-37, como aclara este autor, estas enajenaciones serían recuperadas por el cenobio cisterciense en 1620, mediante un acuerdo con los herederos de Pedro González.

50 La nobleza española, en sus distintos grados, no parece haber sido una gran inversora en deuda pública. Al respecto del fenómeno de la venta de juros en la Castilla Moderna, me remito, entre otros, a Pilar Toвoso Sánchez, La deuda pública castellana durante el Antiguo Régimen (Juros) y su liquidación en el siglo XIX, Madrid, Ministerio de Hacienda, 1987, págs. 206-209; Carlos ÁLvarez Nogal, "Oferta y demanda de deuda pública en Castilla. Juros de alcabalas (1540-1740)", Estudios de Historia Económica, 55 (2009), págs. 9-136. En el caso de la hidalguía gallega, buena parte de las Casas estudiadas cuentan entre sus bienes algunos juros reales. Por ejemplo, la Casa de Outarelo de Valdeorras contaba con dos vinculados en su mayorazgo, situados en las alcabalas de los partidos de Ourense y Ponferrada, v. Isidro García Tato, La casa de Outarelo..., op. cit., págs. 67-68. Ello no obsta para afirmar que la gran mayoría de ingresos de este grupo social gallego estaban basados en rentas forales o asimiladas, y no sobre otros conceptos como diezmos, alcabalas, juros o derechos de señorío. Sobre este particular, v. Vítor Manuel Migués RodRíGuez y Antonio Presedo Garazo, "Los privilegiados..." cap. cit., pág. 278.

51 AHUS, Archivos familiares, 78, leg. 3, núm. 2, doc. 2.

52 Ibídem.

53 Ibídem, leg. 1, núm. 5.

${ }^{54}$ Situada sobre la capilla construida en 1567.
} 
feligresía a cantar la misa mayor los festivos y domingos. Este último recibiría 4 ducados anuales a cambio de velar por el cumplimiento de todo lo dispuesto.

A fin de completar su legado, fundó también una obra pía para dotar a doncellas y estudiantes ${ }^{55}$. Inicialmente, disponía que cada año se casasen dos huérfanas a costa de sus bienes, siempre y cuando una fuese familiar y la otra la más pobre de la feligresía, y que se tratase de personas honestas y de buena vida. Así, en la dote les señalaba 70 ducados al año respectivamente, extraídos del censo que tenía adquirido en Ourense. Como beneficiarias, las jóvenes debían encender dos hachas todas las fiestas y domingos en la parroquia de Lebosende, durante el año posterior a su enlace. Si no cumplían con ello, debían pagar un ducado, destinado a la fábrica de la iglesia, que debía hacerlo en su lugar.

A continuación, establecía que se dotase a tres escolares (dos parientes y uno el más pobre de la feligresía) con 20 ducados anuales para cada uno durante seis años. La condición impuesta era que empleasen bien el dinero y se formasen, pudiendo nombrarse otro candidato si alguno de ellos no cumplía. Además, animaba a que los indicados jóvenes, una vez finalizados sus estudios y siendo ya clérigos de misa, ejercieran en la capellanía instituida. Detrás de este proceso yace la intención de garantizar el acceso de parientes a la Iglesia, a fin de participar en sus riquezas, que retornarían en último término a la familia. De esta forma, la capilla se establecía como un buen punto de partida en la carrera eclesiástica ${ }^{56}$.

Finalmente, constituyó vínculo de todos sus bienes y los agregó a la referida capilla $^{57}$, nombrado por primer patrono y sucesor a su nieto Andrés Alonso de

55 La fundación de capellanías y obras pías se realizaba con un teórico propósito piadoso, pero respondía en último término a unas estrategias económicas y sociales bien calculadas. Al respecto, v. Manuel González Ruiz, "Las capellanías españolas en su perspectiva histórica", Revista de derecho canónico, 5 (1940), págs. 475-501; Juan Pro RuIz, "Las capellanías: familia, iglesia y propiedad en el Antiguo Régimen”, Hispania Sacra, 41 (1989), págs. 585-602. Para el caso gallego, v. Domingo Luis GonZález Lopo, "Un aspecto de la mentalidad religiosa gallega de los siglos XVII y XVIII: la fundación de obras pías", en Manuel Lucas Álvarez et al., Jubilatio. Homenaje de la facultad de geografía e historia a los profesores D. Manuel Lucas Álvarez y D. Ángel Rodríguez González, Santiago de Compostela, Servizo de Publicacións, 1987, págs. 363-374.

56 Enrique Soria Mesa, El cambio inmóvil. Transformaciones y permanencias de una élite de poder. (Córdoba, ss. XVI-XIX), Córdoba, Ediciones de La Posada, 2000, pág. 77.

57 Los vínculos y mayorazgos son instituciones del derecho civil básicas en el crecimiento socio-económico de la nobleza gallega, v. Vítor Manuel Migués Rodríguez y Antonio Presedo Garazo, "Los privilegiados..." cap. cit., págs. 273-276. Sobre las características formales del mayorazgo, su origen, evolución y extinción, v. Bartolomé Clavero SALVAdor, Mayorazgo y propiedad feudal en Castilla, 1369-1836, Madrid, Siglo XXI, 1989. Dicha institución fue una forma de preservar la integridad de los patrimonios ante las particiones obligadas por el paso del tiempo: Enrique Soria Mesa, La nobleza en la España Moderna, Cambio y continuidad, Madrid, Marcial Pons, 2007, págs. 224-244. María Teresa Pérez elaboró un excelente análisis para la región murciana, confirmando la relevancia de la misma en la formación de las grandes casas nobiliarias, v. María Teresa Pérez Picazo, El mayorazgo en la historia económica de Murcia. Expansión, crisis y 
Chantada y después a sus hijos y descendientes legítimos con preferencia de varón a hembra y de mayor a menor. Este sistema establece que, en cada generación, el heredero será el varón primogénito y, de fallecer sin sucesión, lo sean sus hermanos en orden de nacimiento. En el caso de que ninguno de ellos tenga descendencia, heredarán las hermanas ordenadas de la misma forma.

El vínculo agrupaba diversos recursos dedicados al mantenimiento de la capilla y los blindaba contra la disgregación. Así, dentro de los bienes raíces estipulaba 38 viñas, con una extensión aproximada de de 6,21 hectáreas, además de 4 prados, 3 sotos y un nabar en distintos lugares de Leiro. Las rentas agregadas alcanzaban los 58,31 hectolitros de pan, 4 gallinas y 1,01 hl de castañas; estas cantidades estaban fijadas en áreas externas a la localización original del solar, tales como O Irixo, Ribadavia, O Carballiño, Boborás, San Amaro y Maside, todas pertenecientes a la provincia de Ourense. En lo que se refiere a las rentas de vino incluían 23,01 hl de blanco y 5,46 hl de tinto, cobraderas en varios lugares del ayuntamiento de Leiro. Debemos tener en cuenta en el cómputo aquellos caldos que ya se encontraban almacenados y que llenaban las bodegas de la Casa del Candendo, hasta llegar a los 148,83 hl.

El testador poseía cierta cantidad de ganado en régimen de aparcería con campesinos de Leiro y Avión. Las cifras son modestas: 5 bueyes, 3 vacas y 10 becerros, más algunos animales de los que desconoce su número ${ }^{58}$. En el testamento estipula su venta (junto a la de la plata que posee, que no se indica por-

abolición (s. XVII-XIX), Madrid, Ministerio de Agricultura, Pesca e Innovación, 1990, págs. 63-78 Resulta también interesante el análisis de Jesús María Usunáriz sobre su desarrollo y características propias en el Reino de Navarra, v. Jesús María Usunáriz GarayoA, "Mayorazgo, vinculaciones y economías nobiliarias en la Navarra de la Edad Moderna", Iura Vasconiae, 6 (2009), págs. 383-424.

58 Este escaso número indica que los señores no mostraban gran interés por esta actividad (el desconocimiento de Pedro González del número total de animales refuerza la idea). La aparcería solía ser una ocupación económica complementaria de la hidalguía gallega. Diversos estudios han señalado su importancia dentro de los ingresos de este grupo social, que se implicaba en labores especulativas con el ganado. Al respecto, me remito al análisis de Antonio Presedo para diferentes casas del interior de Galicia, que muestra una actividad ganadera mucho más intensiva que la de Candendo. Por ejemplo, las 131 unidades de vacuno, 3 de equino, 155 de ovicápridos, 24 de porcino y 17 de corral que se contabilizan en 1599 en el inventario de Diego López, suegro de Diego Sánchez Taboada, de la Casa de Vilarxoán en Samos, v. Antonio Presedo Garazo, Os devanceiros... op. cit., págs. 93-105, o los 74 de vacuno, 2 de equino, 90 de ovicápridos y 27 colmenas que formaban parte del patrimonio de la Casa da Fraga (Friol) en 1716, v. Antonio Presedo Garazo, "A pequeña fidalguía..." art. cit., págs. 53-87. Desde una perspectiva más general, en los estudios comarcales de Pegerto Saavedra y Ofelia Rey, ya se apuntaba a la importancia del régimen de aparcería en la ganadería de las áreas de Fonsagrada y Ulla, v. Pegerto SaAvedra Fernández, Economía rural antigua en la montaña lucense. El concejo de Burón, Santiago de Compostela, Universidad, 1979, pág. 53; Ofelia Rey Castelao, Aproximación a la historia rural en la comarca del Ulla (ss. XVII y XVIII), Santiago de Compostela, Universidad, 1981, pág. 120. 
menorizadamente) para que el heredero adquiera un censo seguro (a ser posible de origen real).

De la misma forma, Pedro González agregó los juros que tenía adquiridos en diversos lugares de la provincia de Ourense, y que sumaban 153.800 maravedíes anuales ${ }^{59}$. Incluyó también diferentes censos formalizados con vecinos de Leiro y O Irixo, por un valor de 10 ducados. Todo ello con la intención de dotar a la capilla de un sostén económico cimentado más allá de las rentas en especie, asegurando la percepción de dinero líquido.

Así pues, las últimas voluntades que hemos ido refiriendo, resultan capitales a la hora de entender el devenir histórico del solar. En ellas, se fijan aquellos bienes que irán unidos a la capellanía, al objeto de sostener las mandas estipuladas sobre ella, así como las obras pías señaladas para dotar a doncellas y estudiantes. Se trata, en último término, de una relación piadosa que oculta motivos de índole económico y simbólico: el sostenimiento de la memoria del fundador a través de su legado en la feligresía, y la perpetuación de su Casa y estirpe a lo largo de los siglos venideros.

\section{La Casa de Candendo durante el siglo XVII: de la consolidación a la absorción}

Tras el fallecimiento de Pedro González de Candendo, sucedió en el vínculo y capellanía de Nuestra Señora del Rosario su nieto Andrés Alonso de Chantada. Tras la defensa legal de la herencia realizada por su padre Pedro Alonso de Chantada $^{60}$, se encontraba en disposición de administrar el patrimonio legado por su abuelo.

Las fuentes indican que recibió dos foros del Monasterio de San Clodio de Leiro. En el primero, fechado el 19 de abril de $1620^{61}$, los monjes le cedieron una elevada cantidad de bienes, entre los que se encontraban 9,66 hectáreas de viñedo en distintos lugares de la feligresía de Lebosende, una casa con lagar y corral en Osebe, mitad de otra en Villaverde, el lugar y casas de Leiro Pequeño (estos dos en la feligresía de San Pedro de Leiro), dos montes (uno de 0,87 ha, conocido como Das Pedras Chas), un soto de 0,31 ha, y un pardiñeiro en los Casares, para que lo edificase de nuevo o lo dedicase al cultivo de la vid. De la misma forma, en Cuñas, recibió en foro 1,14 ha de viñedos, una pieza de viña y monte y la aldea y casas de Alemparte. A todo lo expuesto, unieron la aceña de Leiro, ubicada en el Río Avia, remozada, con su canal, pie y ruedas.

\footnotetext{
5970.000 maravedíes de las alcabalas de Ourense y 83.800 de las de Viana do Bolo, Souto Bermudo, Verín y Pacios de Monterrei, indicadas con anterioridad.

60 De quien no ha quedado registro alguno de actividad en el archivo.

${ }^{61}$ AHUS, Archivos Familiares, 80, leg. 1, núm. 1, doc. 5.
} 
A cambio de los bienes descritos, la pensión anual fijada era de el quinto de todas las viñas pagado en la Granja de la Groba, 0,20 hl de castañas por el soto, una gallina y cuatro capones por las casas, y el quinto de las viñas que se plantasen en los Casares o un capón en caso de que destinase el lugar a la construcción de un edificio. La renta por el molino ascendía a 4 hl de centeno que debían ser abonados en el San Martín de cada año.

En el propio documento hay una somera referencia a la transacción por la que el cenobio recobra el control del señorío jurisdiccional de Santo Adrao de Vieite, aldea de Cuñas (San Lourenzo da Pena) y la Granja de Vestería de Gomariz, adquirido por Pedro González de Candendo en 1591. De esta forma, los monjes recuperaban, 29 años después, un importante señorío enajenado por la corona durante el reinado de Felipe II.

El 23 de febrero de 1625, los religiosos aforan nuevamente a Andrés Alonso de Chantada una viña de 0,17 ha en la Rigueira da Agra, parroquia de Lebosende, con la condición del pago del quinto de las uvas que produjese ${ }^{62}$.

Finalmente, el 2 de julio de 1646, los mismos protagonistas acordaron que el pago de las reparaciones en la aceña de San Clodio (3.912 reales), no correspondería al hidalgo, ya que cedía su derecho sobre ella al monasterio, y éste, a cambio, le libraba del dispendio y le renovaba todos los foros por dos vidas de reyes $^{63}$.

La falta de escrituras de compraventa señala el fin del crecimiento de la Casa de Candendo, por lo menos, en los niveles en los que se movía Pedro González. La actividad de Andrés se circunscribe a una serie de acuerdos con el monasterio de San Clodio de Leiro, mediante los cuales consigue el control, a través de la fórmula foral, de una cantidad reseñable de viñedos en la feligresía de Lebosende, que asientan todavía más la economía de la Casa, basada en esencia en la explotación y comercialización del vino.

Don Antonio Candendo Pardo Rivadeneira, hijo del anterior, mostró mayor tendencia que su padre a las adquisiciones de bienes raíces, efectuando un total de 6 compras distribuidas en dos breves tramos temporales (una transacción en el año 1676 y las otras cinco entre los años 1681-1682). La cantidad destinada alcanzó los 140 ducados (1.540 reales), cifras modestas en comparación con el ciclo protagonizado por su bisabuelo.

En lo que respecta a su localización y con la ayuda del Mapa 3, podemos comprobar que el interés de Antonio Candendo se centra únicamente en dos áreas, la parroquia de San Tomé de Serantes (ubicada en el ayuntamiento de

\footnotetext{
62 Ibídem, doc. 7.

63 Ibídem, doc. 8.
} 
Leiro, marcado en negro) y la de San Pedro de Xurenzás (Boborás), en color gris oscuro.

Mapa 3. Localización de las compras de don Antonio

Candendo Pardo Rivadeneira (1676, 1681-1682)

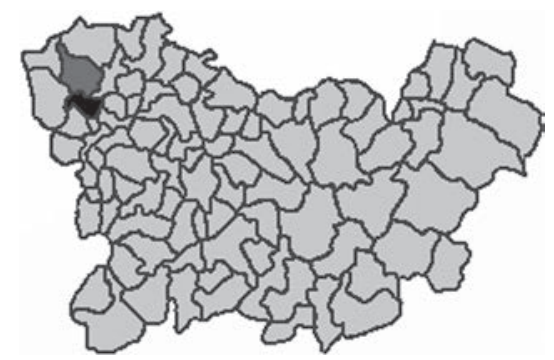

Negro: Ubicación original

Gris oscuro: áreas de expansión

Fuente: Archivo Histórico Universitario de Santiago, Archivos Familiares, 78-82.

A la luz de los datos reflejados en el Gráfico 5, constatamos que el interés de don Antonio se ciñe a reducidas participaciones sobre bienes raíces. En 1676 lleva a cabo una compra de un prado y una pequeña viña en Xurenzás ${ }^{64}$. En el bienio 1681-1682 la atención sigue centrada en esta misma área, con la adquisición de prados y la mitad de una casa ${ }^{65}$, además de la obtención de un nabal en San Tomé de Serantes ${ }^{66}$.

Gráfico 5. Composición de los bienes raíces adquiridos por don Antonio Candendo Pardo Rivadeneira, en ducados (1676, 1681-1682)

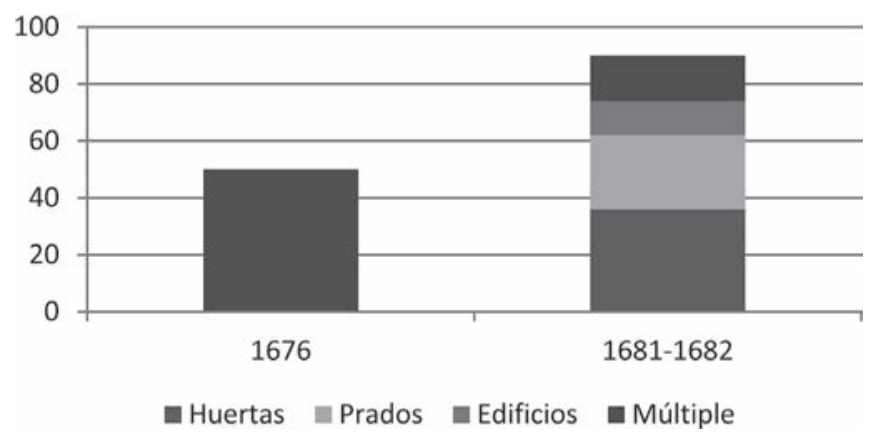

Fuente: Archivo Histórico Universitario de Santiago, Archivos Familiares, 78-82.

\footnotetext{
64 Ibídem, 82, leg. 1, núm. 1, doc. 38.

65 Ibídem, docs. 40, 42 y 44.

66 Ibídem, 81, leg. 4, núm. 2, doc. 17.
} 
A ello hay que unir que, el 18 de agosto de 1665 recibió una importante cesión de un vecino, Andrés do Porto, para subsanar el impago la renta atrasada, hasta un total del equivalente a 27,44 hl de centeno, que le debían por nueve años. El documento incluía varias casas, viñas y parte de un molino, ubicados en San Pedro de Xurenzás ${ }^{67}$. Todo ello manifiesta la contracción en la política expansionista de los Candendo, reveladada ya en los primeros sucesores de Pedro González, y continuada por don Antonio, que prefirió centrarse en tareas más administrativas.

Así, el 26 de octubre de 1657 arrendó a Bernardo da Serra y Clara de Corval, 0,44 ha de viñas en distintas zonas de Lebosende, a cambio de 88 reales y 2 gallinas anuales, a lo largo de nueve años ${ }^{68}$. Los Candendo no eran proclives a la utilización de este tipo de escritura, que conllevaba una constante renovación de las condiciones contractuales y una menor estabilidad en la renta, al contrario que el foro.

El 31 de agosto de 1668 pacta una permuta con Amaro Álvarez y Catalina Janeira, naturales de San Xusto de Beresmo (Avión), en la que don Antonio les cedía una casa y diferentes bienes que poseía en la mencionada localidad, a cambio de una serie de viñedos sitos en la feligresía de Vieite con una extensión de 0,52 ha, además de una casa terreña con su cocina, corral, parra y salidas, de dominio directo del monasterio de San Clodio ${ }^{69}$. De la misma forma, el 30 de enero de 1677 permutó 0,17 ha de viñedo en Corval a Benito Santiago, por 0,37 ha en la Groba (todo ello en Lebosende), más 185 ducados en concepto de compensación. Estos viñedos eran de fuero de $5^{\circ}$ de la Granja de la Groba (dependiente del cenobio $)^{70}$. Ambos movimientos indican interés en recursos próximos a la zona de influencia de la Casa de Candendo, que permiten liberarla de otros que suponen una mayor distancia y por lo tanto, menor atractivo.

En lo que se refiere a su práctica crediticia, tan sólo tenemos el testimonio de dos censos redimibles: el primero fue concedido al capitán Blas López Mosquera y su mujer María Vaamonde, naturales de Coedo (San Lorenzo de Pena, Cenlle) y estipulaba unos réditos de 25 ducados anuales por 500 de principal $^{71}$. El segundo se pactó con dos vecinos de Lebosende, Antonio Méndez y María Álvarez, que hipotecaron diferentes bienes, entre los que se encontraba una casa y 0,13 ha de viña en la misma parroquia, y se obligaron a pagar 3 ducados anuales por 60 que les entregó el hidalgo ${ }^{72}$.

Un ejemplo de la notoriedad conseguida por esta familia se declara en la descripción que se hace del lugar del Candendo en un inventario de bienes de don

67 Ibídem, 82, leg. 1, núm.1, doc. 31

68 Ibídem, 80, leg. 3, núm. 3, doc. 1

69 Ibídem, 81, leg. 1, núm. 1, doc. 16

70 Ibídem, 80, leg. 2, núm. 1, doc. 46.

71 Ibídem, 78, leg. 1, núm. 14.

72 Ibídem, leg. 3, núm. 2, doc. 2 
Antonio $^{73}$. En él se indica que existía una casa de sobrado con salas, aposentos, galería de arcos y piedra labrada con seis o siete ventanas, corredor y reja de hierro, despensa y torre con bodega de piedra, todo de sillería ${ }^{74}$. Aunque la relación es parca, resulta suficiente para apreciar como se trata de un conjunto necesariamente diferenciado de las edificaciones labriegas, producto de generaciones que fueron modificando diversos aspectos de la casa, adecuándola a su estatus social.

El sucesor de don Antonio fue el capitán don Juan Antonio Candendo Pardo Rivadeneira. Según nos indican las escrituras, a lo largo de su vida mostró un mayor nivel de actividad que su padre y su abuelo, tanto en el apartado referido a las adquisiciones de bienes raíces como, y sobre todo, a la defensa legal del patrimonio heredado. No sólo por el largo conflicto entablado con don Diego Quiroga por la dote de doña Benita Candendo, sino por diversos litigios llevados a cabo contra campesinos renteros que incumplían los pagos correspondientes.

Este hidalgo ejecutó un total de 9 compras entre los años 1689 y 1698, en las que invirtió 339 ducados (3729 reales), lo que supone más del doble del dinero empleado por su padre, don Antonio. Éstas se concentran, como muestra el Mapa 4, en cuatro feligresías: en el actual ayuntamiento de Leiro (en negro): los lugares de Candendo en San Miguel de Lebosende, y Balboa en Santa María de Lamas; en Maside (gris medio): el lugar de Dacón en Santa María de Amarante; y, finalmente, en Boborás (gris oscuro): el lugar de Penedo en Santa María de Xuvencos.

Mapa 4. Localización de las compras de don Juan Antonio Candendo Pardo Rivadeneira (1689-1698)

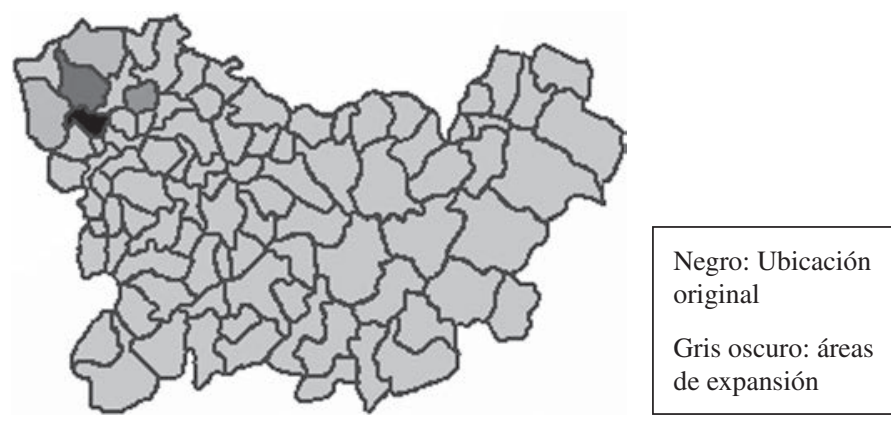

Fuente: Archivo Histórico Universitario de Santiago, Archivos Familiares, 78-82.

\footnotetext{
73 Este documento ha llegado a nosotros a través de una copia sin fecha, extraída por don Ignacio Quiroga y Taboada. Ibídem, leg. 1., núm. 26.

${ }^{74}$ No es la intención de este trabajo examinar los inventarios de la Casa ni el ordenamiento de su vida cotidiana, en relación a ello, nos remitimos a nuestro análisis de un tardío documento que pormenoriza el estado del solar en el siglo XIX, v. Iago RodríGuez PaLmeiro, "Fidalgos gallegos...", op. cit. [en prensa].
} 
Si nos detenemos a comprobar la estructura de las operaciones, siguiendo el Gráfico 6, vemos que en el primer período (1689-1694), don Juan Antonio realiza una inversión de 125 ducados. De éstos, 112 se dedican a diversos bienes radicados en Balboa (Lamas) ${ }^{75}$, consistentes en una parte de monte, un prado y un nabal; los 13 restantes a una porción de viña y lobio en Candendo (Lebosende) ${ }^{76}$, y una compra de dos labradíos y un pedazo de monte en Dacón (Amarante) ${ }^{77}$. El segundo período, que discurre entre 1695 y 1698, presenta un alza en el dispendio hasta los 214 ducados. En primer lugar, destina 150 a dos mitades de casa ${ }^{78}$, una junto al atrio de la iglesia de Lebosende y otra en el lugar de Corbal; y el resto del dinero (64) a varias fincas labradías en Penedo, (Xuvencos) $)^{79}$.

Gráfico 6. Composición de los bienes raíces adquiridos por don Juan Antonio Candendo Pardo Rivadeneira, en ducados (1689-1698)

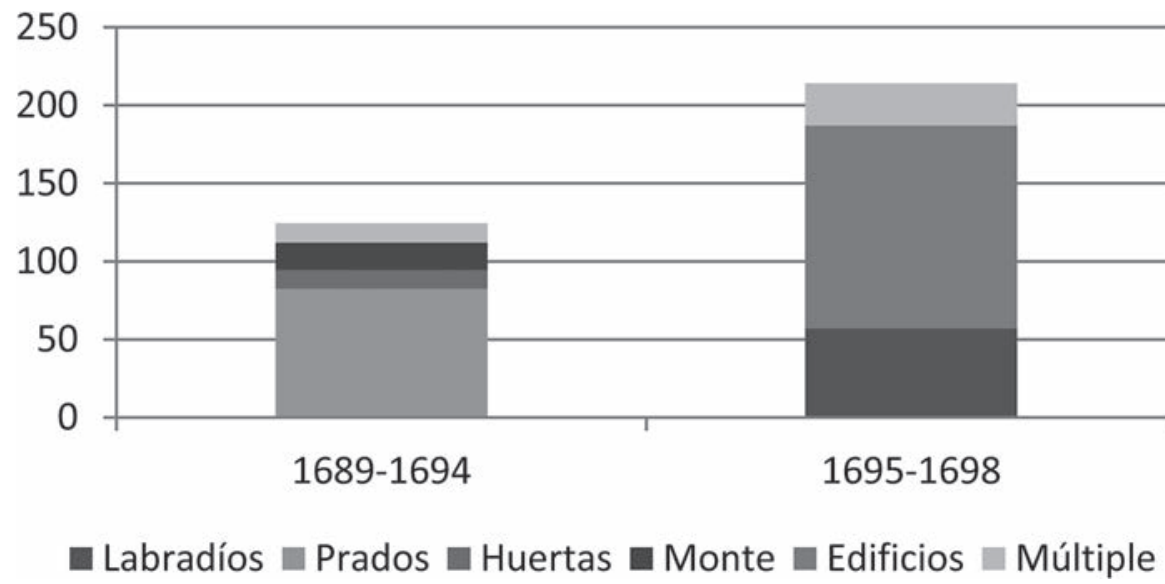

Fuente: Archivo Histórico Universitario de Santiago, Archivos Familiares, 78-82.

Por el contrario, el empleo de foros es una estrategia muy poco utilizada. Tan sólo tenemos constancia de uno, realizado en 1708, a favor de su hija natural doña Ana María Candendo, en el que se estipulan una casa terreña más media hectárea de viñedo en Ibedo (Santo Adrao de Vieite) y 0,13 ha del mismo cultivo

\footnotetext{
75 AHUS, Archivos Familiares, 81, leg. 3, núm. 3, doc. 3, 4 y 5.

76 Con una pensión del quinto de las uvas a la Granja de la Groba (San Clodio de Leiro). Ibídem, 80, leg. 2, núm. 1, doc. 64 .

77 Ibídem, 81, leg. 8, núm. 1 doc. 8.

78 Con pensiones de media y una libra de cera, respectivamente, a la Granja de la Groba. Ibídem, 80, leg. 2, núm. 1, docs. 65 y 66.

79 Ibídem, 82, leg. 2, núm. 2, docs. 1 y 2.
} 
en Veiga da Agra (San Breixo de Berán) ${ }^{80}$. En este contrato se refleja claramente el interés por asegurar su manutención, a través de la cesión de una serie de bienes con los que poder subsistir en un nivel acorde a su grupo social. Esta idea se refuerza al final del documento, donde se incluye la cláusula que establece la reintegración de los bienes en el patrimonio original en el caso de que doña Ana falleciese sin descendencia.

De la misma forma que sus antecesores, don Juan dedicó parte de sus recursos a la conformación de censos. En 1703, concede uno a favor del licenciado don Pedro de Lara, Tesorero General de la Casa de Lemos, en el que le entrega 33.000 reales, con unos réditos que importan 1650 anuales, con el aval de algunas casas y bienes en la villa de Monforte de $\operatorname{Lemos}^{81}$. De menor calado es el que suscribe en 1707 con don José de Quiroga y Bandín y don Bernardino Rivas, por un total de 1.000 ducados, a cambio de 30 reales pagados anualmente e hipotecados sobre diversas viñas en Lebosende ${ }^{82}$.

En síntesis, si bien el último de los señores de Candendo sigue interesado por la adquisición de bienes raíces en el área de Candendo y otras más alejadas, se trata de intervenciones muy concretas y limitadas en el tiempo. En su mayor parte, destaca la compra de edificios y prados, dejando de lado los viñedos, montes, huertas y labradíos. Es otro eslabón más del declive inversor experimentado por la familia durante el siglo XVII, hasta que los Quiroga Taboada tomen el mando una vez concluida la centuria.

Como hemos podido comprobar a lo largo de este apartado, el mercado de la tierra, y, en menor medida, las rentas y los créditos, poseen una elevada importancia en la economía de la Casa y se configuran como factores relevantes de su crecimiento. Queda por determinar, con un trabajo más exhaustivo, el efecto que sobre esta expansión tuvieron otros agentes: la gestión comercial de las rentas, la reproducción social o la participación de nuestros protagonistas en la vida comunitaria y el poder local.

\section{CONCLUSIONES}

La familia Candendo hunde sus raíces en el siglo XV, asentada en el lugar del mismo nombre, feligresía de San Miguel de Lebosende. Si bien en un principio depende en gran medida de la influencia del monasterio de San Clodio, sus posesiones crecen gradualmente a lo largo del XVI, impulsadas por la actividad

\footnotetext{
80 Ibídem, 81, leg. 1, núm. 1, doc. 17.

81 Ibídem, 78, leg. 3, núm. 1, doc. 8. Los réditos serían entregados un año después a don Diego de Quiroga y Taboada, en compensación de la deuda acumulada por la dote de doña Benita de Candendo. Ibídem, doc. 9.

82 Ibídem, 80, leg. 3, núm.2, doc. 3.
} 
mercantil de Pedro González de Candendo, fundador de una capellanía y obra pía en la iglesia parroquial, a la que une un vínculo de bienes para sostener sus cargas. Al mismo tiempo, y gracias a la voluntad del mencionado Pedro, se produce una extensión del señorío jurisdiccional a través de adquisiciones de bienes eclesiásticos, enajenados por la corona en un contexto de necesidad monetaria para financiar la política exterior de Felipe II. Este ritmo expansivo se ve frenado a lo largo del XVII, donde los sucesores se centran en tareas de índole administrativo, a fin de consolidar el dominio. Paralelamente y de forma progresiva, decae el mantenimiento de la capilla y su legado, por la merma de las rentas y la ineficacia de su gestión. Ello conlleva asimismo, el endeudamiento de la familia y la pérdida de sus señoríos, que retornarán en último momento a su original poseedor, el monasterio de San Clodio de Leiro.

Si bien en un primer momento desconocemos las estrategias de reproducción social, a partir del XVII se centran en la figura del primogénito como heredero del vínculo y capellanía, buscando entronques con otras familias hidalgas, principalmente del ámbito urbano, relegando a los hermanos segundones al clero y a las hermanas al matrimonio con miembros del mismo grupo social. Mediante el enlace de doña Benita, la familia será absorbida a comienzos del XVIII por los Quiroga Taboada, que garantizarán la posesión del solar a través de un acuerdo con la mujer del último señor de la Casa, don Juan Antonio, fallecido sin descendencia. Desde de ese momento, los bienes pasarán a formar parte de un conglomerado patrimonial con epicentro en la provincia de Pontevedra y serán gestionados por un administrador nombrado al efecto. 
HIDALGOS DEL RIBEIRO DE AVIA: LA CASA DE CANDENDO EN

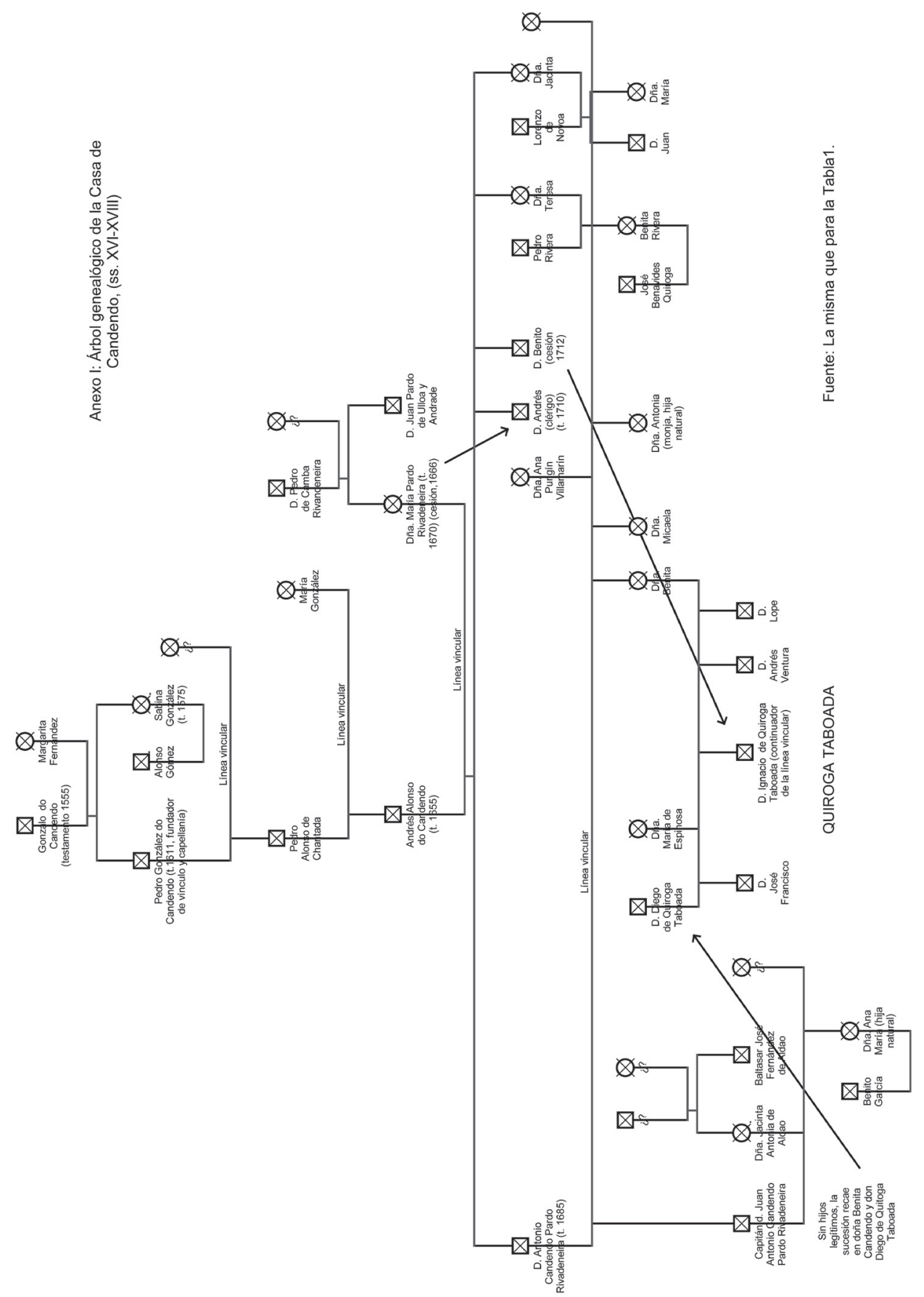




\section{BIBLIOGRAFÍA}

Álvarez Nogal, Carlos, "Oferta y demanda de deuda pública en Castilla. Juros de alcabalas (1540-1740)", Estudios de Historia Económica, 55 (2009), págs. 9-136.

Castro Pérez, Felipe, A Casa de Valladares: formación e evolución do patrimonio dunha familia dominante na Pontevedra do Antigo Réxime, Pontevedra, Deputación Provincial, 2004.

Clavero Salvador, Bartolomé, Mayorazgo y propiedad feudal en Castilla, 1369-1836, Madrid, Siglo XXI, 1989.

Díaz Castroverde-Lodeiro, José Luis, El señorío de de la Casa de Sonán en su jurisdicción, gobierno y hacienda durante los siglos XVI al XX, Padrón, Novo Século, 1995.

Díaz Castroverde-Lodeiro, José Luis, Morgados e xurisdicións na terra e condado de Taboada, séculos XV-XVIII, Guntín, Asociación de Amigos do Mosteiro de Ferreira de Pallares, 2012.

Domínguez Castro, Luis, Viños, viñas e xentes do Ribeiro. Economía e patrimonio familiar, 1810-1952, Vigo, Edicións Xerais, 1992.

Eiras Roel, Antonio, "Régimen subforal e hidalguía intermediaria". Prólogo al libro de Carmen Quintáns Vázquez, El dominio de San Martín Pinario ante la Desamortización, Santiago de Compostela, Secretariado de Publicaciones de la Universidad, 1972, págs. 10-12.

Faya Díaz, María Ángeles, "Los señoríos eclesiásticos gallegos y la venta de jurisdicciones en tiempos de Felipe II", en José L. Pereira Iglesias y Jesús M. González Beltrán (eds.), Felipe II y su tiempo, Actas de la V Reunión Científica de la Asociación Española de Historia Moderna, Cádiz, Servicio de Publicaciones de la Universidad, 1999, págs. 101-115.

Fernández González, Frutos, O padrón de San Clodio de 1580: estudio histórico e onomástico, Santiago de Compostela, Asociación Galega de Onomástica, 2008.

Fernández Suárez, Gonzalo Francisco, La nobleza gallega entre los siglos XIV-XV. Los Sarmiento, condes de Ribadavia, Santiago de Compostela, El Eco Franciscano, 2002.

Fernández Suárez, Gonzalo Francisco, "Los Condes de Ribadavia durante el reinado de Carlos V”, Estudios Mindonienses, 21 (2005), págs. 49-313.

García Guerra, Elena, "Moneda en España en los siglos XVI-XVII", en Alfredo Alvar Ezquerra et al., La economía en la España Moderna, Madrid, Istmo, 2006, págs. 201-240.

García Tato, Isidro, La Casa de Outarelo en Valdeorras. Formación y desarrollo de su patrimonio (siglos XIV-XX), Madrid, Gráficas Loureiro, 2001.

González Lopo, Domingo Luis, "Un aspecto de la mentalidad religiosa gallega de los siglos XVII y XVIII: la fundación de obras pías", en Manuel Lucas Álvarez et al., Jubilatio. Homenaje de la facultad de geografía e historia a los profesores D. Manuel Lucas Álvarez y D. Ángel Rodríguez, González, Santiago de Compostela, Servizo de Publicacións, 1987, págs. 363-374.

González Lopo, Domingo Luis, Mentalidades religiosas en la Galicia del Barroco, Santiago, Xunta de Galicia, 2002.

González Paz, Carlos Andrés (ed.), El Pazo de Tovar: espacios, perspectivas, tiempos, Santiago de Compostela, CSIC, 2012 (Col. Monografías de "Cuadernos de Estudios Gallegos", 12). 
González Ruiz, Manuel, "Las capellanías españolas en su perspectiva histórica", Revista de derecho canónico, 5 (1940), págs. 475-501.

Goy Diz, Ana, O Mosteiro de San Clodio de Leiro, A Coruña, Fundación Caixa Galicia, 2005.

Guilarte Zapatero, Alfonso María, El régimen señorial en el siglo XVI, Valladolid, Universidad de Valladolid, 1987.

Iglesias Blanco, Anastasio Santos, La Casa de Amarante, siglos XVI-XIX, Santiago de Compostela, Universidade de Santiago, 2008.

Leirós de la Peña, Paz: “La casa de Fontefiz”, Boletín Auriense, XXIII (1993), págs. 197-237.

López Díaz, María, “Alteraciones en el mapa jurisdiccional gallego durante la Edad Moderna: las desmembraciones eclesiásticas del siglo XVI”, Estudios mindonienses, 7 (1991), págs. 559-588.

López Díaz, María, Jurisdicción e Instituciones locales de la Galicia meridional (XVI-XVIII), Vigo, Servizo de Publicacións da Universidade de Vigo, 2011.

Lucas Álvarez, Manuel y Lucas Domínguez, Pedro, El monasterio de San Clodio do Ribeiro en la edad media: estudio y documentos, Sada, Edicións do Castro, 1996.

Marcos Martín, Alberto, "Enajenaciones por precio del patrimonio regio en los siglos XVI y XVII. Balance historiográfico y perspectivas de análisis", en Roberto J. López et al., Balance de la historiografía modernista: 1973-2001. Actas del VI Coloquio de Metodología Histórica Aplicada (Homenaje al profesor Antonio Eiras Roel), Santiago de Compostela, Xunta de Galicia, 2003, págs. 419-443.

Migués Rodríguez, Vítor Manuel, "O dominio da Casa de San Fiz de Asma: Evolución e inversión dun dominio fidalgo durante o antigo réxime", Cuadernos de Estudios Gallegos, XLII (1995), págs. 39-67.

Migués Rodríguez, Vítor Manuel, A fidalguía galega: un breve enxergar histórico a través da Casa de San Fiz de Asma e agregadas, Santiago de Compostela, Tórculo, 1997.

Migués Rodríguez, Vítor Manuel, As terras, as pousas e os vinculeiros. A fidalguía galega na Época Moderna, Sada, Edicións do Castro, 2002.

Migués Rodríguez, Vítor Manuel, "La intermediación foral sobre los patrimonios eclesiásticos: la superación de una hipérbole historiográfica”, en María López Díaz (ed.), Estudios en homenaje al profesor José M. Pérez García, vol. 2, Vigo, Servizo de Publicacións da Universidade de Vigo, 2009, págs. 189-206.

Migués Rodríguez, Vítor Manuel y Presedo Garazo, Antonio, "Los privilegiados”, en Isidro Dubert García (coord.), Historia de la Galicia Moderna, Santiago, Universidad de Santiago, 2012, págs. 269-317.

Moxó y Ortiz de Villajos, Salvador, "La desamortización eclesiástica del siglo XVI", Anuario de historia del derecho español, 31 (1961), págs. 327-362.

Pardo de Guevara y Valdés, Eduardo, De linajes, parentelas y grupos de poder: aportaciones a la historia social de la nobleza bajomedieval gallega, Madrid, Fundación Cultural de la Nobleza Española, 2012, págs. 323-362.

Pérez Picazo, María Teresa, El mayorazgo en la historia económica de Murcia. Expansión, crisis y abolición (s. XVII-XIX), Madrid, Ministerio de Agricultura, Pesca e Innovación, 1990. 
Prado Díaz, Benjamín de, El linaje de la Casa de Tor, introducción y estudio de Eduardo Pardo de Guevara y Valdés, Lugo, Deputación Provincial, 2007.

Presedo Garazo, Antonio, Os devanceiros dos pazos: economía e estratexias sociais da pequena fidalguía rural na Galicia interior (ss. XVI-XVIII), Santiago de Compostela, Sotelo Blanco, 1997.

Presedo Garazo, Antonio, "A pequena fidalguía rural e a parcería de gando: A Casa da Fraga de San Xiao de Carballo —Friol_, 1680-1800", Cuadernos de Estudios Gallegos, 109 (1997), págs. 53-78.

Presedo Garazo, Antonio, "Los ingresos económicos de un hidalgo gallego: rentas y negocios de don Blas María Rubiños (1772-1810)", Investigaciones Históricas. Época moderna y contemporánea, 19 (1999), págs. 11-37.

Presedo Garazo, Antonio, Dueños y señores de casas, torres y pazos, 1500-1900: (contribución al estudio de la fidalguía gallega), tesis doctoral inédita, Santiago de Compostela, 2001.

Presedo Garazo, Antonio, "La capacidad crediticia de la nobleza provincial del Reino de Galicia durante los siglos XVI-XVIII", Lucensia, 29 (2004), págs. 231-244.

Presedo Garazo, Antonio, "Patrimonio y administración privada en la hidalguía gallega durante el Antiguo Régimen a través del ejemplo de la Casa de Noceda", Estudis d'Història Agraria. Homenatge al Dr. Emili Giralt i Raventós, 17 (2004), págs. 719-728.

Presedo Garazo, Antonio, A fidalguía galega ante a crise do antigo réxime: (1812-1868), Santa Comba, TresCtres, 2006.

Presedo Garazo, Antonio, "O clero secular galego de orixe fidalga na época moderna: unha poderosa elite local”, Compostellanum, 52 (2007), págs. 651-670.

Presedo Garazo, Antonio, A fidalguía galega: estudos sobre a reprodución social dos fidalgos na Galicia Moderna, Santiago de Compostela, Lóstrego, 2008.

Presedo Garazo, Antonio, Nobleza y régimen señorial en Galicia: la Casa de Montaos en los siglos XVI y XVII, Santiago de Compostela, USC Editora Académica, 2012, págs. 80-81

Presedo Garazo, Antonio, "Hidalgos y casas hidalgas en la provincia de Ourense en la Edad Moderna", en María López Díaz (ed.), Cuadernos Feijonianos de Historia Moderna IV, Santiago de Compostela, Andavira, 2013, págs. 65-105.

Pro Ruiz, Juan, "Las capellanías: familia, iglesia y propiedad en el Antiguo Régimen", Hispania Sacra, 41 (1989), págs. 585-602.

Rey Castelao, Ofelia, Aproximación a la historia rural en la comarca del Ulla (ss. XVII y XVIII), Santiago de Compostela, Universidad, 1981.

Rionegro Fariña, Isolina, "Una familia de poder de la élite orensana: los Boán”, en María López Díaz (ed.), Cuadernos Feijonianos de Historia Moderna IV, Santiago de Compostela, Andavira, 2013, págs. 107-127.

Rodríguez Palmeiro, Iago, "La fidalguía en el interior de la provincia de Lugo. Siglos XVIXIX”, en Eliseo Serrano Martín (coord.), De la tierra al cielo. Líneas recientes de investigación en historia moderna, Madrid, CSIC, págs. 839-856.

Rodríguez Palmeiro, Iago, "La vida cotidiana de la fidalguía gallega en el interior de la provincia de Lugo. Las casas de Virigo (Navia de Suarna), Hermida y Moreiras (Quiroga). Siglos XVIII y XIX”, en María José Pérez Álvarez, Laureano Manuel Rubio Pérez, Al- 
fredo Martín García (eds.); Francisco Fernández Izquierdo (col.), Campo y campesinos en la España Moderna. Culturas políticas en el mundo hispano, vol. II, León, Fundación Española de Historia Moderna, págs. 1497-1505.

Rodríguez Palmeiro, Iago, "Fidalgos gallegos en el ocaso de la modernidad. Apuntes de su patrimonio a través de los inventarios de la Casa-Torre de Basille (Baralla) y la Casa de Candendo (Leiro). Siglos XVIII-XIX", [en prensa].

Rodríguez Palmeiro, Iago, "Los archivos familiares y la historia rural. Revisión historiográfica y perspectivas de futuro" [en prensa].

Saavedra Fernández, Pegerto, Economía rural antigua en la montaña lucense. El concejo de Burón, Santiago de Compostela, Universidad, 1979.

Saavedra Fernández, Pegerto, "Un aspecto de las crisis de subsistencias en la Galicia del Antiguo Régimen: las ventas de tierra, en Antonio Eiras Roel et al., La historia social de Galicia en sus fuentes de protocolo, Santiago de Compostela, 1981, págs. 181-204.

Saavedra Fernández, Pegerto, Economía, política y sociedad en Galicia. La provincia de Mondoñedo, 1480-1830, Santiago de Compostela, Consellería da Presidencia, 1985.

Saavedra Fernández, Pegerto, La vida cotidiana en la Galicia del Antiguo Régimen, Barcelona, Crítica, 1994.

Soria Mesa, Enrique, La venta de señoríos en el Reino de Granada bajo los Austrias, Granada, Universidad, 1995.

Soria Mesa, Enrique, El cambio inmóvil. Transformaciones y permanencias de una élite de poder. (Córdoba, ss. XVI-XIX), Córdoba, Ediciones de La Posada, 2000.

Soria Mesa, Enrique, La nobleza en la España Moderna, Cambio y continuidad, Madrid, Marcial Pons, 2007.

Toboso Sánchez, Pilar, La deuda pública castellana durante el Antiguo Régimen (Juros) y su liquidación en el siglo XIX, Madrid, Ministerio de Hacienda, 1987.

Usunáriz Garayoa, Jesús María, "Mayorazgo, vinculaciones y economías nobiliarias en la Navarra de la Edad Moderna”, Iura Vasconiae, 6 (2009), págs. 383-424.

Villares Paz, Ramón, La propiedad de la tierra en Galicia, 1500-1936, Madrid, Siglo XXI, 1982. 